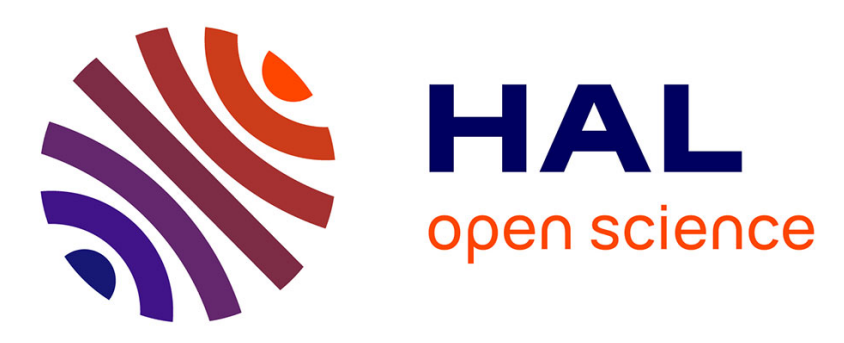

\title{
Hardness and toughness of sodium borosilicate glasses via Vickers's indentations
}

Marina Barlet, Jean-Marc Delaye, Thibault Charpentier, Mickael Gennisson, Daniel Bonamy, Tanguy Rouxel, Cindy Rountree

\section{To cite this version:}

Marina Barlet, Jean-Marc Delaye, Thibault Charpentier, Mickael Gennisson, Daniel Bonamy, et al.. Hardness and toughness of sodium borosilicate glasses via Vickers's indentations. Journal of NonCrystalline Solids, 2015, 417-418, pp.66-79. 10.1016/j.jnoncrysol.2015.02.005 . cea-01366698

\section{HAL Id: cea-01366698 https: / hal-cea.archives-ouvertes.fr/cea-01366698}

Submitted on 15 Sep 2016

HAL is a multi-disciplinary open access archive for the deposit and dissemination of scientific research documents, whether they are published or not. The documents may come from teaching and research institutions in France or abroad, or from public or private research centers.
L'archive ouverte pluridisciplinaire HAL, est destinée au dépôt et à la diffusion de documents scientifiques de niveau recherche, publiés ou non, émanant des établissements d'enseignement et de recherche français ou étrangers, des laboratoires publics ou privés. 


\title{
Hardness and toughness of sodium borosilicate glasses via Vickers's indentations
}

\author{
Marina Barlet ${ }^{\mathrm{a}, \mathrm{b}}$, Jean-Marc Delaye ${ }^{\mathrm{c}}$, Thibault Charpentier ${ }^{\mathrm{d}}$, Mickael Gennisson ${ }^{\mathrm{c}}$, Daniel Bonamy ${ }^{\mathrm{a}, \mathrm{b}}$, \\ Tanguy Rouxel ${ }^{\mathrm{e}}$, Cindy L. Rountree ${ }^{\mathrm{a}, \mathrm{b}, *}$ \\ a CEA, IRAMIS, SPEC, SPHYNX, CEA Saclay, CNRS UMR 3680, F-91191 Gif-sur-Yvette, France \\ b CEA, IRAMIS, SPCSI, Complex Systems and Fracture, CEA Saclay, F-91191 Gif-sur-Yvette, France \\ c CEA, DEN, DTCD, SECM, LMPA, CEA Marcoule, BP17171, 30207 Bagnols-sur-Cèze, France \\ d CEA, IRAMIS, NIMBE, LSDRM, CEA Saclay, CNRS UMR 3685, F-91191 Gif-sur-Yvette, France \\ e Département Mécanique et Verres, Institut de Physique de Rennes, UMR 6251, Université de Rennes 1, Campus de Beaulieu, 35042 Rennes cedex, France
}

\section{A R T I C L E I N F O}

\section{Article history:}

Received 14 October 2014

Received in revised form 16 January 2015

Accepted 8 February 2015

Available online 2 April 2015

\section{Keywords:}

Sodium borosilicate glasses:

Hardness;

Fracture toughness;

Glass structure

\begin{abstract}
A B S T R A C T
This study investigates the mechanical response of sodium borosilicate (SBN) glasses as a function of their chemical composition. Vickers's indentation tests provide an estimate of the material hardness $\left(H_{V}\right)$ and indentation fracture toughness $\left(K_{C}^{V I F}\right)$ plus the amount of densification/shear flow processes. Sodium content significantly impacts the glass behavior under a sharp indenter. Low sodium glasses maintain high connected networks and low Poisson's ratios $(\nu)$. This entails significant densification processes during deformation. Conversely, glasses with high sodium content, i.e. large $\nu$, partake in a more depolymerized network favoring deformation by shear flow. As a consequence, indentation patterns differ depending on the processes occurring. Densification processes appear to hinder the formation of half-penny median-radial cracks. Increasing $\nu$ favors shear flow and residual stresses enhance the development of half-penny median-radial cracks. Hence, $K_{C}^{\text {VIF }}$ decreases linearly with $\nu$.
\end{abstract}

(c) 2015 Elsevier B.V. All rights reserved.

\section{Introduction}

Portable electronic devices frequently require thin lightweight glass used to protect the internal electronics. As such these glasses need to be resilient to external pressures. A common test to study these protective glasses is micro-indentation from which two important and standard measurements are extracted: (1) hardness (material's resistance to permanent deformation, $H_{V}$ ) and (2) indentation fracture toughness (material's resistance to fracture, $K_{C}$ ). These tests classify the glass's mechanical response into two groups: anomalous and normal behavior. Anomalous glasses predominantly densify under high external pressures. These glasses have a low atomic packing density; thus, the relative movement of the $\mathrm{Si}-\mathrm{O}-\mathrm{Si}$ linkage under pressure leads to the volume shrinkage [1-4]. On the other hand, normal behavior implies volume conserving shear flow. This is evidenced by a plastic flow generating pile-up of matter in the vicinity of the indentation without volume change [5-8]. Typically broken bonds and cations favor this phenomenon [9]. The degree at which a glass behaves normally and anomalously significantly depends on the glass' chemical composition [9-11].

Residual indention patterns vary significantly with the chemical composition [12]. Typically, anomalous glasses exhibit cone crack,

\footnotetext{
* Corresponding author at: CEA, IRAMIS, SPEC, SPHYNX, CEA Saclay, CNRS UMR 3680, F91191 Gif-sur-Yvette, France.

E-mail address: cindy.rountree@cea.fr (C.L. Rountree).
}

whereas normal glasses predominantly exhibit radial-median cracks [9]. Previous, in-situ indentation studies of normal and anomalous glasses emphasize variations in deformation processes and effects in the residual stress levels [13]. Variations in contribution of densification versus shear flow alter the indentation shape, the crack appearance and the toughness measurements [5,11,13]. Furthermore, Hagan [7,8,14] highlighted that flow lines which appear in the indentation imprints can pile-up to produce seed cracks for median and radial cracks. In order to discriminate between shear flow and densification in glasses, researchers developed a simple test to estimate the amount of permanent densification under an indenter in glasses and the amount of plastic flow [15-18].

This paper investigates the mechanical response due to indentation in eight SBN glasses of modulated chemical composition. The glass's mechanical response depends on the glass structure. Imaging of the indents provides a means to obtain the hardness $\left(H_{V}\right)$, the crack appearance probability $\left(P_{C}\right)$ and the indentation fracture toughness ( $K_{C}^{V I F}$, VIF implies Vickers's indentation fracture). To understand how matter flows beneath the indenter, AFM imaging before and after annealing discriminates between densification and shear flow mechanisms. For the reader's convenience, Appendix A provides a list of symbols, there meaning, and when appropriate the equation used to calculate them.

The following sections detail experimental techniques: (1) glass fabrication, (2) techniques used in understanding the glass properties (density, elastic moduli, MAS NMR); and (3) measuring and extracting information on the glass's response to Vickers's indenter. The Results 
Table 1

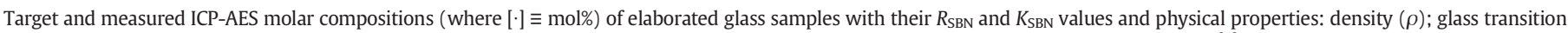

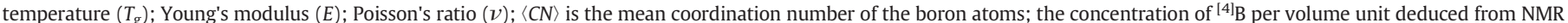

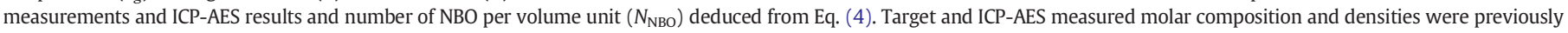

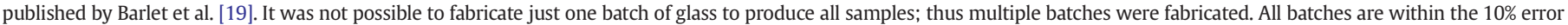
of the ICP-AES measurement. Each SBN glass composition has an associated symbol in the subsequent figures. Glass's names won't be recalled on the figures below for clarity.

\begin{tabular}{|c|c|c|c|c|c|c|c|c|c|c|c|c|c|c|c|c|}
\hline \multirow[t]{2}{*}{ Name } & \multicolumn{3}{|c|}{ Target values } & \multicolumn{3}{|c|}{ Measured via ICP-AES } & \multirow[t]{2}{*}{$R_{\mathrm{SBN}}$ measured } & \multirow[t]{2}{*}{$K_{\mathrm{SBN}}$ measured } & \multirow{2}{*}{$\begin{array}{l}\rho \\
\left(\frac{\mathrm{g}}{\mathrm{cm}^{3}}\right)\end{array}$} & \multirow{2}{*}{$\begin{array}{l}\mathrm{T}_{g} \\
\left({ }^{\circ} \mathrm{C}\right)\end{array}$} & \multirow{2}{*}{$\begin{array}{l}\mathrm{E} \\
(\mathrm{GPa})\end{array}$} & \multirow[t]{2}{*}{$v$} & \multirow[t]{2}{*}{$\langle C N\rangle$} & \multirow{2}{*}{$\begin{array}{l}{ }^{[4]} \mathrm{B} \cdot 10^{21} \\
\left(\mathrm{~cm}^{-3}\right)\end{array}$} & \multirow{2}{*}{$\begin{array}{l}N_{\mathrm{NBO}} \cdot 10^{21} \\
\left(\mathrm{~cm}^{-3}\right)\end{array}$} & \multirow[t]{2}{*}{ Symbols } \\
\hline & {$\left[\mathrm{SiO}_{2}\right]$} & {$\left[\mathrm{B}_{2} \mathrm{O}_{3}\right]$} & {$\left[\mathrm{Na}_{2} \mathrm{O}\right]$} & {$\left[\mathrm{SiO}_{2}\right]$} & {$\left[\mathrm{B}_{2} \mathrm{O}_{3}\right]$} & {$\left[\mathrm{Na}_{2} \mathrm{O}\right]$} & & & & & & & & & & \\
\hline SBN 12 & 59.6 & 28.2 & 12.2 & 59.6 & 23.9 & 16.5 & 0.69 & 2.5 & 2.463 & 543 & 80.1 & $0.209_{ \pm 0.004}$ & 3.60 & 6.78 & 1.022 & $\triangle$ \\
\hline SBN 25 & 50.7 & 23.9 & 25.4 & 52.6 & 20.6 & 26.8 & 1.30 & 2.5 & 2.545 & 535 & 80.3 & $0.238_{ \pm 0.001}$ & 3.70 & 7.22 & 5.91 & $\nabla$ \\
\hline SBN 30 & 47.3 & 22.3 & 30.4 & 51 & 20.1 & 28.6 & 1.44 & 2.5 & 2.541 & 494 & 74.7 & $0.255_{ \pm 0.002}$ & 3.68 & 6.77 & 7.36 & $\triangleleft$ \\
\hline SBN 35 & 44 & 20.6 & 35.4 & 46.9 & 18.6 & 34.5 & 1.85 & 2.5 & 2.537 & 467 & 76.7 & $0.264_{ \pm 0.0014}$ & 3.62 & 5.65 & 11.21 & $\nabla$ \\
\hline SBN 14 & 67.8 & 18 & 14.2 & 70 & 15.8 & 14.2 & 0.89 & 4.4 & 2.474 & 588 & 81.8 & $0.212_{ \pm 0.004}$ & 3.72 & 5.49 & 1.34 & * \\
\hline SBN 63 & 63.2 & 16.8 & 20.0 & 66.7 & 14.1 & 19.2 & 1.35 & 4.7 & 2.524 & 573 & 81.9 & $0.226_{ \pm 0.001}$ & // & // & // & 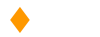 \\
\hline SBN 59 & 59.2 & 15.8 & 25 & 61.1 & 13.3 & 25.5 & 1.91 & 4.5 & 2.534 & 539 & 77.2 & $0.230_{ \pm 0.01}$ & 3.79 & 5.22 & 7.39 & 0 \\
\hline SBN 55 & 55.3 & 14.7 & 30 & 58.0 & 12.9 & 29.1 & 2.25 & 4.5 & 2.538 & 505 & 72.8 & $0.251_{ \pm 0.006}$ & 3.76 & 4.86 & 7.49 & $\star$ \\
\hline
\end{tabular}

section presents structural properties, $H_{V}, P_{C}, K_{C}^{V I F}$, and variations in contribution of densification and shear flow processes in the permanent deformation of sodium borosilicate (SBN) glasses. The Discussion section expounds the glass structure with their mechanical response to a Vickers's indenter. This part also compares and contrasts results presented in Sellappan et al. paper [18]. Furthermore, this section estimates the residual stresses induced during loading and after total unloading.

\section{Experimental procedure}

This section contains three subsections. It first describes the elaboration process of the glasses studied herein. Then, it details tests used to analyze the glasses' structural/material properties. Finally, it presents tests to understand the material response to microindentation.

\subsection{Glass elaboration}

Studies herein employ eight sodium borosilicate (SBN) glasses elaborated in-house [19]. During the elaboration process, manual homogenization of the silica $\left(\mathrm{SiO}_{2}\right)$, orthoboric acid $\left(\mathrm{H}_{3} \mathrm{BO}_{3}\right)$, and sodium carbonate $\left(\mathrm{Na}_{2} \mathrm{CO}_{3}\right)$ powders occurs. Platinum/gold $(\mathrm{Pt} / \mathrm{Au})$ crucibles retain the homogenized powder during the glass melting process. The formation of the glass melt undergoes three principle steps. Initially, the dehydration of the orthoboric acid takes place at $200{ }^{\circ} \mathrm{C}$ for $2 \mathrm{~h}$. Next, the decarbonation of sodium carbonate $\mathrm{Na}_{2} \mathrm{CO}_{3}$ occurs at $800{ }^{\circ} \mathrm{C}$ for $3 \mathrm{~h}$ to avoid bubble formation. The final stage produces the glass melt. Depending on the glass composition, this stage occurs between $1100{ }^{\circ} \mathrm{C}$ and $1300{ }^{\circ} \mathrm{C}$ for $3 \mathrm{~h}$. To avoid residual stress during the cooling process, the glass melt is transferred into a preheated carbon crucible whose temperature is approximately $T_{g}$ (glass transition temperature). Subsequently, the glass melt enters in a second furnace and cools at a slower rate $\left(10^{\circ} \mathrm{C} / \mathrm{h}\right)$ to release the residual stresses.

ICP-AES measurements (conducted by a third party, Prime Verre) verify the chemical compositions of the SBN glasses. Table 1 summarizes the target and measured values. ICP-AES measurements give approximately $10 \%$ error for each oxide. Several batches were fabricated to produce all samples. All of them are within the $10 \%$ error of the ICP-AES measurement. The glasses are classified depending on their $R_{\mathrm{SBN}}=\frac{\left[\mathrm{Na}_{2} \mathrm{O}\right]}{\left[\mathrm{B}_{2} \mathrm{O}_{3}\right]}$ and $K_{\mathrm{SBN}}=\frac{\left[\mathrm{SiO}_{2}\right]}{\left[\mathrm{B}_{2} \mathrm{O}_{3}\right]}$ ratios.

\subsection{Structural investigation}

A glass's mechanical response is linked intrinsically to its structure. Thus, it is important to understand and quantify several glass parameters including density, elastic moduli, and the environment around the boron atoms.

\subsubsection{Density, $\rho$}

The densities of the glasses are estimated by Archimedes' principle. The geometry is a cylinder of thickness $10 \mathrm{~mm}$ and diameter $30 \mathrm{~mm}$. Tests are conducted at ambient conditions using a hydrostatic balance. Initially, the glass samples are weighted in air $\left(m_{d}\right)$ and water $\left(m_{w}\right)$. Then by multiplying by the density of water $\left(\rho_{w}\right)$ one can arrive at the density of the sample $(\rho)$ :

$$
\rho=\frac{m_{d}}{m_{d}-m_{w}} \times \rho_{w}
$$
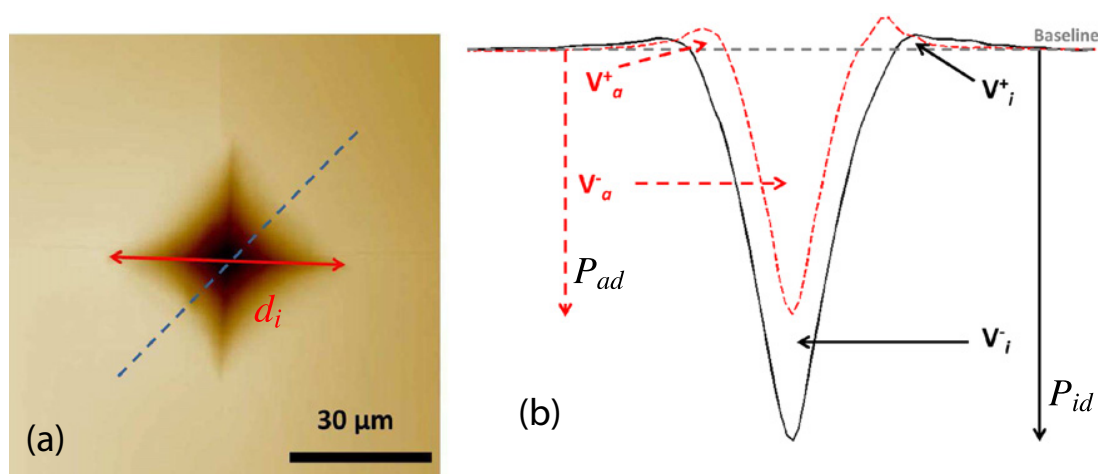

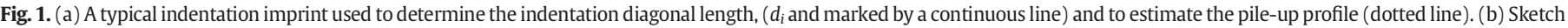

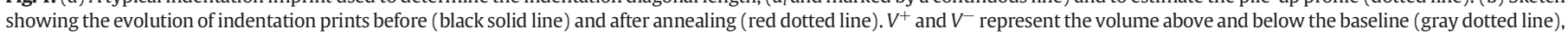
respectively. 


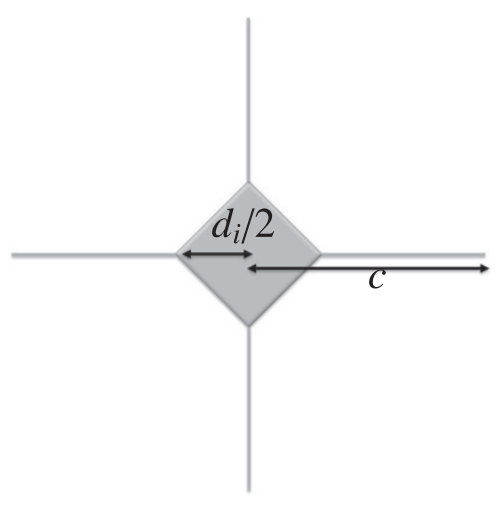

Fig. 2. Sketch of a Vickers's indent and notations used to define $K_{C}^{V I F}: d_{i}$ is the indentation diagonal length from one indent and $c_{i}$ is the crack length measured from the indentation center.

\subsubsection{Young modulus and Poisson's ratio}

Ultrasonic echography techniques provide a means to estimate the elastic moduli and Poisson's ratio using a $5 \mathrm{MHz}$ piezoelectric transducer. Tests invoke the same specimens as for the density tests. The specimen thickness is precisely determined using a digital micrometer with an accuracy of $\pm 1 \mu \mathrm{m}$. The ultrasonic velocities of longitudinal $\left(V_{L}\right)$ and transverse $\left(V_{T}\right)$ acoustic waves are calculated from the thickness and transit time values. The Young modulus $(E)$ and Poisson's ratio $(\nu)$ are then related to $V_{L}$ and $V_{T}$ via:

$E=\rho * \frac{\left(3 V_{L}^{2}-4 V_{T}^{2}\right)}{\left(V_{L} / V_{T}\right)^{2}-1}$

$\nu=\frac{V_{L}^{2}-2 V_{T}^{2}}{2\left(V_{L}^{2}-V_{T}^{2}\right)}$

Table 1 presents $E$ and $\nu$ for the eight different SBN glasses.

\subsection{3. ${ }^{[11]} B$ MAS NMR}

${ }^{[11]} \mathrm{B}$ magic angle spinning (MAS) nuclear magnetic resonance (NMR) spectra were collected on a Bruker AVANCE II 500WB spectrometer operating at a Larmor frequency of $160.14 \mathrm{MHz}$ (magnetic field $11.72 \mathrm{~T}$ ) using a $4 \mathrm{~mm}$ (outer diameter of $\mathrm{ZrO}_{2}$ rotor) Bruker (boronfree) CPMAS probe. For each SBN composition, cylinder samples $\left(0.8 \times 2.96 \mathrm{~mm}^{2}\right)$ were spun at a frequency of $14 \mathrm{kHz}$, and a recycle delay of $2 \mathrm{~s}$ and a pulse length of $1 \mu \mathrm{s}$ (tip angle of about $20^{\circ}$ ) were used to ensure quantitative data of the spectra. Data processing occurred via an in-house code (for details see reference [20]). ${ }^{[11]} \mathrm{B}$ magic angle spinning nuclear magnetic resonance (MAS NMR) experiments provide complementary information on the glass structure via revealing the boron environment. The high symmetry around ${ }^{[4]} \mathrm{B}$

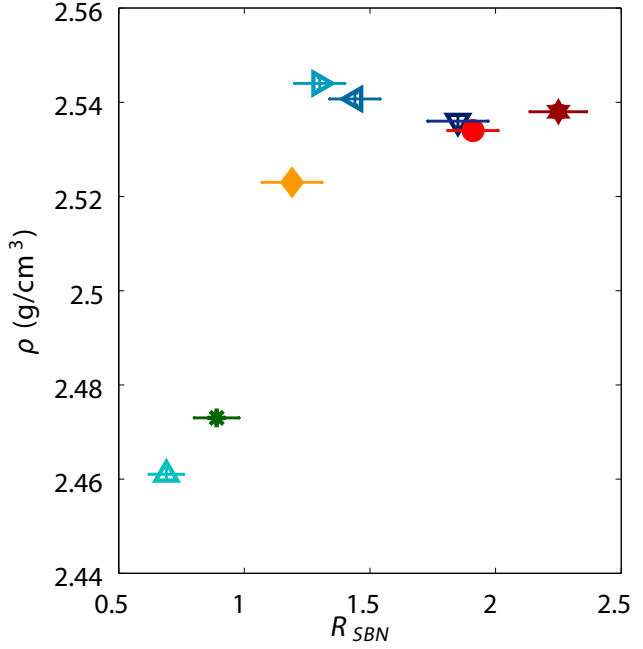

Fig. 3. Density, $\rho$, as a function of $R_{\mathrm{SBN}}$.

leads to a SMALL quadrupolar coupling $(0.2-0.4 \mathrm{MHz})$ in contrast to the trigonal ${ }^{[3]} \mathrm{B}$ unit $(2.5-2.7 \mathrm{MHz})$. Thus, the boron environment reveals the proportions of ${ }^{[3]} \mathrm{B}$ and ${ }^{[4]} \mathrm{B}$.

Two assumptions enable scientist to estimate the number of non-bridging oxygen atoms (note a NBO can be either Si or B atoms) in a SBN glass. First, each ${ }^{[4]} \mathrm{B}$ structural unit has one $\mathrm{Na}^{+}$ion attaching to it, and the $\mathrm{Na}^{+}$ion acts as a network compensator. Second, all the other $\mathrm{Na}^{+}$ions act as network modifiers. This gives one NBO per network modifying $\mathrm{Na}^{+}$ion. The equation to calculate this is:

$N_{\mathrm{NBO}}=N_{\mathrm{Na}}-N_{[4]}$

$N_{\mathrm{Na}}, N_{\mathrm{NBO}}$, and $N_{[4]_{B}}$ are the total number of $\mathrm{Na}^{+}$ions, the number of $\mathrm{NBO}$, and the number of $\mathrm{Na}^{+}$acting as network compensators (equivalently the number of ${ }^{[4]} \mathrm{B}$ ) in the system, respectively. Table 1 presents these results.

\subsection{Mechanical testing}

This subsection details the experiments used to obtain the glass's mechanical response due to a Vickers's micro-indenter. The first subsection presents the geometry of the samples. It first presents the instrument and techniques used for the Vickers's indentations. Then, it details techniques for imaging imprints. The following sections detail how analyzing the images reveals the hardness, crack resistance, and indentation fracture toughness. Finally, the last subsection details the annealing procedures and how to extract the information concerning the densification and shear flow processes.

Table 2

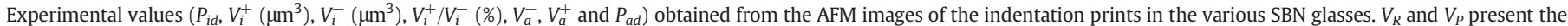

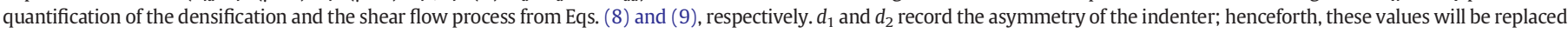
by $d_{i}$, the average of the two.

\begin{tabular}{|c|c|c|c|c|c|c|c|c|c|c|c|c|c|c|c|}
\hline \multirow[t]{2}{*}{ Name } & \multicolumn{2}{|c|}{$\begin{array}{l}\text { Diagonals } d_{i} \\
(\mu \mathrm{m})\end{array}$} & \multirow[t]{2}{*}{$\begin{array}{l}\mathrm{c} \\
(\mu \mathrm{m})\end{array}$} & \multirow[t]{2}{*}{$\begin{array}{l}H_{V} \\
(\mathrm{MPa})\end{array}$} & \multirow[t]{2}{*}{$\begin{array}{l}C_{R} \\
(\mathrm{~g})\end{array}$} & \multirow[t]{2}{*}{$\begin{array}{l}K_{C}^{V I F} \\
\left(\mathrm{MPa} \cdot \mathrm{m}^{1 / 2}\right)\end{array}$} & \multirow[t]{2}{*}{$\begin{array}{l}P_{i d} \\
(\mu \mathrm{m})\end{array}$} & \multirow[t]{2}{*}{$\begin{array}{l}V_{i}^{+} \\
\left(\mu \mathrm{m}^{3}\right)\end{array}$} & \multirow[t]{2}{*}{$\begin{array}{l}V_{i}^{-} \\
\left(\mu \mathrm{m}^{3}\right)\end{array}$} & \multirow[t]{2}{*}{$\begin{array}{l}V_{i}^{+} / V_{i}^{-} \\
(\%)\end{array}$} & \multirow[t]{2}{*}{$\begin{array}{l}V_{a}^{-} \\
\left(\mu \mathrm{m}^{3}\right)\end{array}$} & \multirow[t]{2}{*}{$\begin{array}{l}V_{a}^{+} \\
\left(\mu \mathrm{m}^{3}\right)\end{array}$} & \multirow[t]{2}{*}{$\begin{array}{l}P_{a d} \\
(\mu \mathrm{m})\end{array}$} & \multirow[t]{2}{*}{$V_{R}$} & \multirow[t]{2}{*}{$V_{P}$} \\
\hline & $d_{1}$ & $d_{2}$ & & & & & & & & & & & & & \\
\hline SBN 12 & 10.4 & 10.6 & $37_{ \pm 2}^{300 \mathrm{~g}}$ & $8200_{ \pm 300}$ & 270 & $0.98_{ \pm 0.09}^{300}$ & 1.012 & 5 & 36.7 & 13.6 & 4 & 14.4 & 0.665 & 52.8 & 16.3 \\
\hline SBN 25 & 12.0 & 12.2 & $14.1_{ \pm 0.6}$ & $6340_{ \pm 100}$ & 26 & $0.69_{ \pm 0.07}$ & 1.037 & 13 & 54.8 & 23.7 & 12 & 31.1 & 0.805 & 30.8 & 25.6 \\
\hline SBN 30 & 12.7 & 13.3 & $15_{ \pm 1}$ & $5400_{ \pm 200}$ & 32 & $0.61_{ \pm 0.06}$ & 1.19 & 17 & 62 & 27.4 & 16.3 & 47.2 & 0.912 & 12.6 & 28.6 \\
\hline SBN 35 & 13.5 & 13.7 & $16.7_{ \pm 0.8}$ & $4900_{ \pm 300}$ & 29 & $0.56_{ \pm 0.06}$ & 1.2 & 19.1 & 70.1 & 27.3 & 15.5 & 60.2 & 1.08 & 9 & 32.4 \\
\hline SBN 14 & 11.2 & 11.3 & $11.9_{ \pm 3}$ & $7200_{ \pm 300}$ & 45 & $0.81_{ \pm 0.08}$ & 0.88 & 7 & 35.2 & 19.8 & 10 & 26.1 & 0.822 & 34.3 & 11.3 \\
\hline SBN 63 & 12 & 11.9 & $13_{ \pm 3}$ & $6400_{ \pm 200}$ & 38 & $0.74_{ \pm 0.05}$ & 0.99 & 10.8 & 49.3 & 21.9 & 9 & 31.7 & 0.844 & 32 & 25.6 \\
\hline SBN 59 & 13.1 & 13.1 & $13.9_{ \pm 0.9}$ & $5370_{ \pm 90}$ & 37 & $0.71_{ \pm 0.07}$ & 1.03 & 12 & 55.3 & 21.7 & 15 & 41.7 & 0.846 & 30 & 16.3 \\
\hline SBN 55 & 14 & 13.25 & $15.1_{ \pm 4}$ & $4900_{ \pm 100}$ & 40 & $0.65_{ \pm 0.05}$ & 1.1 & 12 & 56.8 & 21.1 & 15 & 43.9 & 0.857 & 28 & 15.8 \\
\hline
\end{tabular}




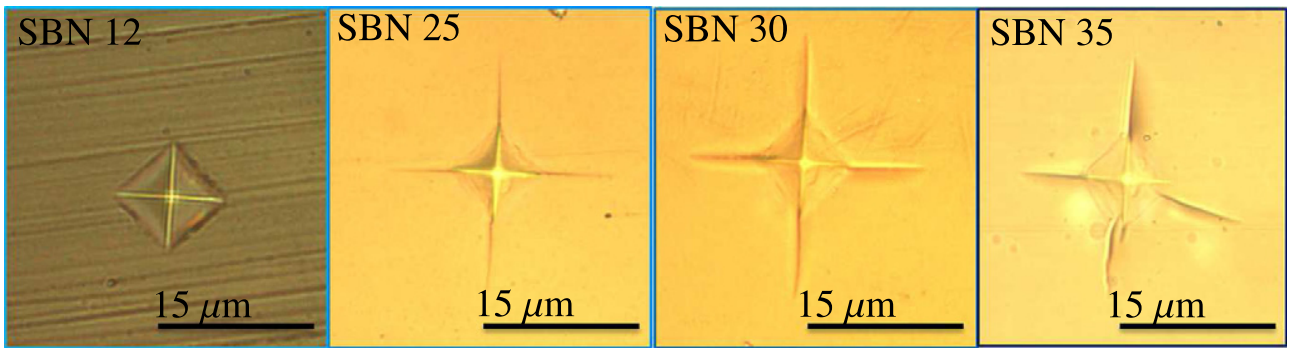

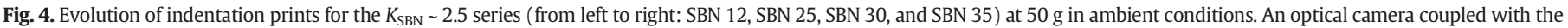
Vickers's indenter captures the imprints within 5 min after indentation.

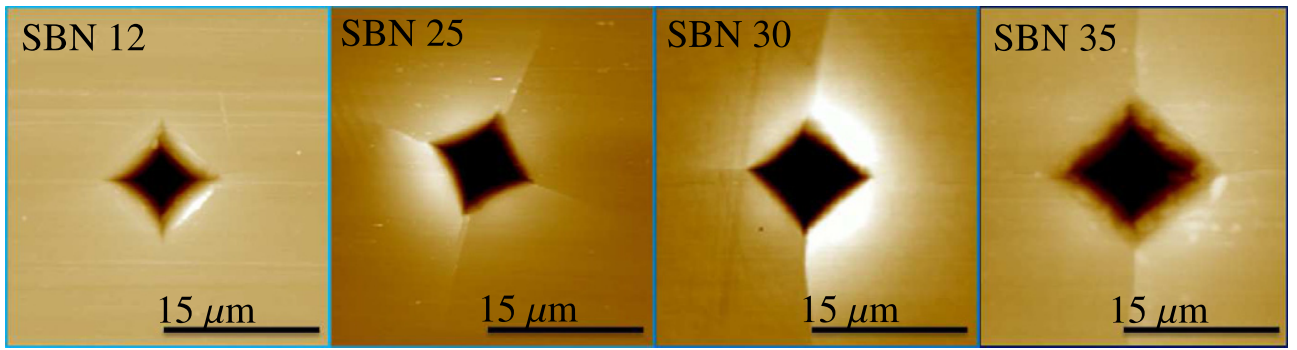

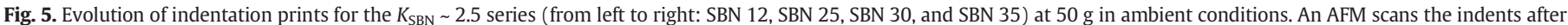
indentation.

\subsubsection{Sample preparation}

Indentation experiments require samples with two parallel surfaces. Samples herein are rectangular parallelepipeds of size $5 \times 5 \times 25 \mathrm{~mm}^{3}$. Indentations take place on one of the $5 \times 25 \mathrm{~mm}^{2}$ faces. Surface quality affects the crack behavior of glasses; therefore diamond grinding disks optically polish the samples.

\subsubsection{Mechanical testing by Vickers's indentation}

Vickers's microindentation tests customarily give sample hardness $\left(H_{V}\right)$ and indentation fracture toughness $\left(K_{C}^{V I F}\right)$. Indentations occur at $22 \pm 1{ }^{\circ} \mathrm{C}$ in air (ambient conditions for humidity) with an Aton Paar MHT-10 hardness tester. Before each set of indents, an Aton Paar MHT-10 hardness tester underwent a series of tests on standard samples to ensure proper regulations. The indentation load $(P)$, varies from $25 \mathrm{~g}$ to $300 \mathrm{~g}$. The dwelling time at maximum load is $15 \mathrm{~s}$ for all tests. Experimental conditions remain the same during the tests.

\subsubsection{Image acquisition of indentation imprints}

An atomic force microscopy (Dimension Icon Nanoscope V Bruker) images the indentation imprints in PeakForce Tapping mode. The AFM cantilever (Bruker's RTESPA) is a silicon tip with a nominal radius of $8 \mathrm{~nm}$ and nominal force constant of $40 \mathrm{~N} / \mathrm{m}$. The scan size is sufficiently large with respect to the imprint size to permit correcting the AFM image planarity. Typically, the image sizes are greater than twice the indentation diagonal. The estimated errors for measuring the length by AFM are less than $2 \%$ in the $X$ and $Y$ directions and about $2 \%$ in the $\mathrm{Z}$ direction. Post-image analysis reveals 4 parameters per indent (Fig. 1):

1. Residual indentation depth: $P_{i d}$

2. Indentation diagonal length: $d_{i}$

3. Indentation volume: $V_{i}^{-}$, volume measured below the free surface

4. Volume of pile-up: $V_{i}^{+}$, volume measured above the free surface.

\subsubsection{Hardness determination}

Vickers's hardness measures the material ability to resist permanent deformation induced by a harder material. Analyzing the indentation imprints reveals a permanent deformation due to the Vickers's indenter at specific loads. Knowing the diagonal length of the imprint indentation $\left(d_{i}\right.$, Fig. $\left.1, \mathrm{a}\right)$ and $P$, the Vickers's hardness is:

$H_{V}=\frac{1.8544 P}{d_{i}^{2}}$.

At least 10 indentations occur at $50 \mathrm{~g}(0.49 \mathrm{~N})$ maximum load. Indentations which do not form well-developed cracks are rejected.

\subsubsection{Crack resistance, $C_{R}$}

Vickers's indentation can cause cracks to initiate off the corners of the indenter. The probability of crack appearance, $P_{C}$, is the average number of radial cracks per corner for a given load. This is conducted

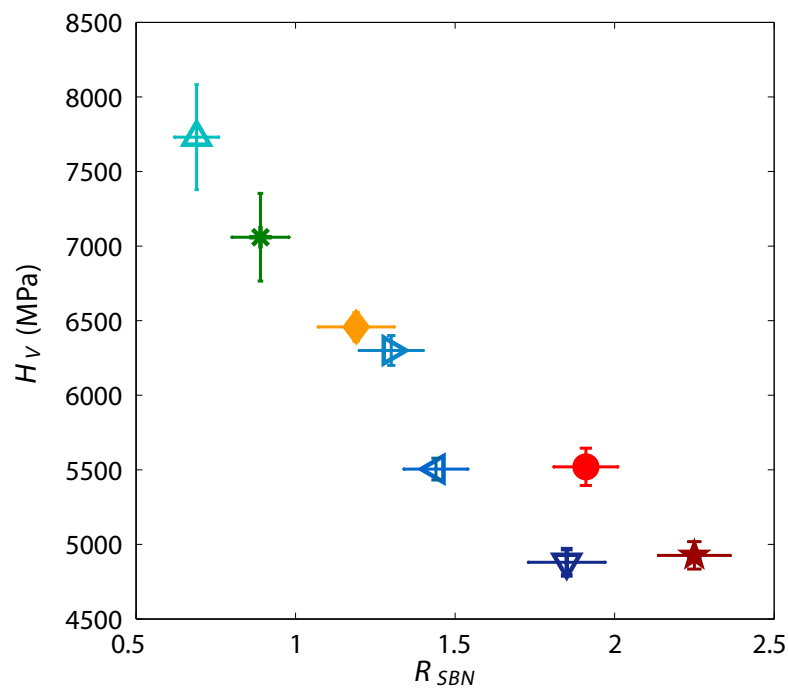

Fig. 6. Hardness values, $H_{V}$, versus $R_{\mathrm{SBN}}$ for SBN glasses (at $50 \mathrm{~g}$ during $15 \mathrm{~s}$ in ambient conditions). 


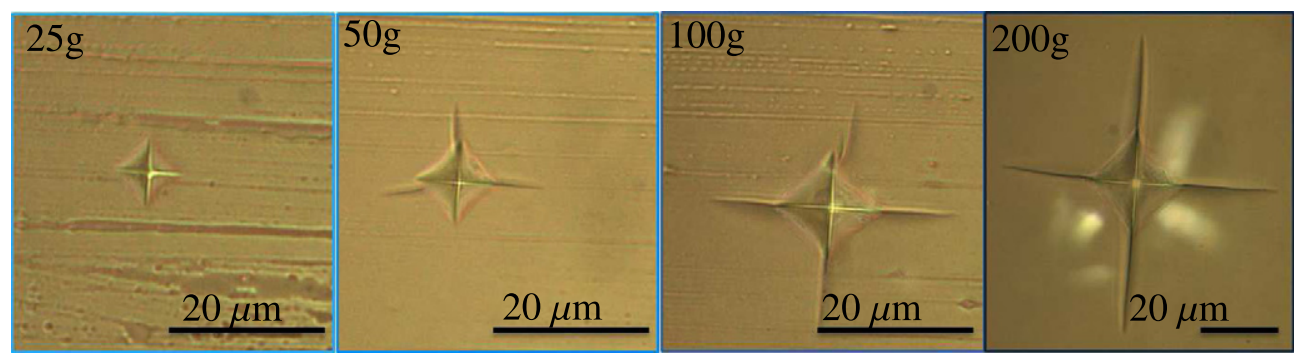

Fig. 7. Set of optical images in SBN 14 acquired at increasing loads. As the load increases, the number of cracks initiating off the corners of the indenter increases.

at multiple loads. The load where $P_{C}$ exceeds $50 \%$ defines the crack resistance, $C_{R}[21]$.

\subsection{6. $K_{C}$ measurements from indentation}

Fracture toughness, $K_{C}$, defines the material's resistance to failure under vacuum. Herein, estimates for $K_{C}$ arise by studying the length of the cracks generated off the corners of the indenter (see Fig. 2). (Note: Henceforth, $K_{C}$ arising from indentation studies will be referred to as $K_{C}^{I N D}$ ) Many models exist in literature to estimate $K_{C}^{I N D}$ by indentation [12,22-31]. There are two predominate models: half-penny median-radial cracks $\left(c>1.25 d\right.$; $c$ being the average distance $\left(\left\langle c_{i}\right\rangle\right)$ from the indentation center to the crack tip and $d$ the mean of $\left\langle d_{i}\right\rangle$ values obtained for one indent) and Palmqvist cracks $(c<1.25 d)$.

Lawn's et al. model assumes well-developed half-penny medianradial cracks $[12,23]$. These cracks emerge when the load is sufficiently high insuring $c>1.25 d$. Palmqvist cracks, on the other hand, exists when $c<1.25 d$. These cracks extend from opposite indentation corners; however, they do not connect to each other [32]. In general, half-penny median-radial cracks models follow the following relationship [12,23, 32,33]:

$K_{C}^{I N D}=\alpha\left(\frac{E}{H_{V}}\right)^{n} \frac{P}{(c)^{3 / 2}}$

where $\alpha$ is a calibration constant. $n$ depends on the model. Standard values of $n$ are 0 [27], 0.4 [26,32], 0.5 [28], and 2/3 [12]. Weber et al. uses Lawn's ASTM report to arrive at the following equation:

$K_{C}^{V I F}=0.057 \times H_{V} \times \sqrt{d / 2}\left(\frac{E}{H_{V}}\right)^{0.4} \times\left(\frac{c}{(d / 2)}\right)^{-3 / 2}$.

This is predominantly valid for well-defined indentation patterns with crack lengths fulfilling the condition $c>1.25 d$. However, Weber suggests that it is also acceptable for Palmqvist cracks as it resembles
Lankford et al. equation [29,30,32]. This is favorable as SBN 12 does not fulfill the condition of $c>1.25 d$ at $50 \mathrm{~g}(0.49 \mathrm{~N})$; yet, all other samples meet this requirement. If the indents do not have 4 cracks, the indentation pattern is not included in the averages. (It is note worthy that error bars in the figures correspond to one standard deviation of the mean values [34].) A force of $50 \mathrm{~g}$ will be invoked for all $K_{C}^{V I F}$ measurements (with an exception for SBN 12 where higher loads are applied). Due to stress corrosion cracking (ambient conditions for humidity), c can vary with time after indentation [28]. To avoid substantial errors in the $K_{C}^{V I F}$ evaluation, an optical microscope images the surface crack pattern within 5 min after indentation.

\subsection{Complementary measurements of Vickers' indentations: densification and shear flow processes}

The high pressures induced by the sharp indenter yields both reversible (elastic) response and irreversible (plastic) deformations. The irreversible component is mainly due to densification or volume conserving shear flow [5,16,35-39]. Yoshida et al. [16] propose a 3D technique to estimate the fraction of densification from the comparison of the indentation imprints before and after the annealing: Upon annealing, the indent shape will change due to the recovery of densified areas [16,37,40,41]. This procedure has recently been extended by Sellappan et al. [18] to quantify the amount of volume conserving shear flow $\left(V_{P}\right)$. The following subsections present the methods applied to quantify first the densification and subsequently the isochoric shear flow process.

\subsubsection{Densification estimation}

Studying the volume ratio before and after annealing provides an easy way to estimate the amount of densified volume. As revealed above, post-processing of AFM scans of the indent imprints reveals 4 parameters (Fig. 1): $P_{i d}, d_{i}, V_{i}^{-}$, and $V_{i}^{+}$. Subsequently, annealing the samples at $0.9 T_{g}$ for $2 \mathrm{~h}$ in air relieves a significant proportion of the densified regions $[16,37,40,41]$. After annealing, imprints are imaged.
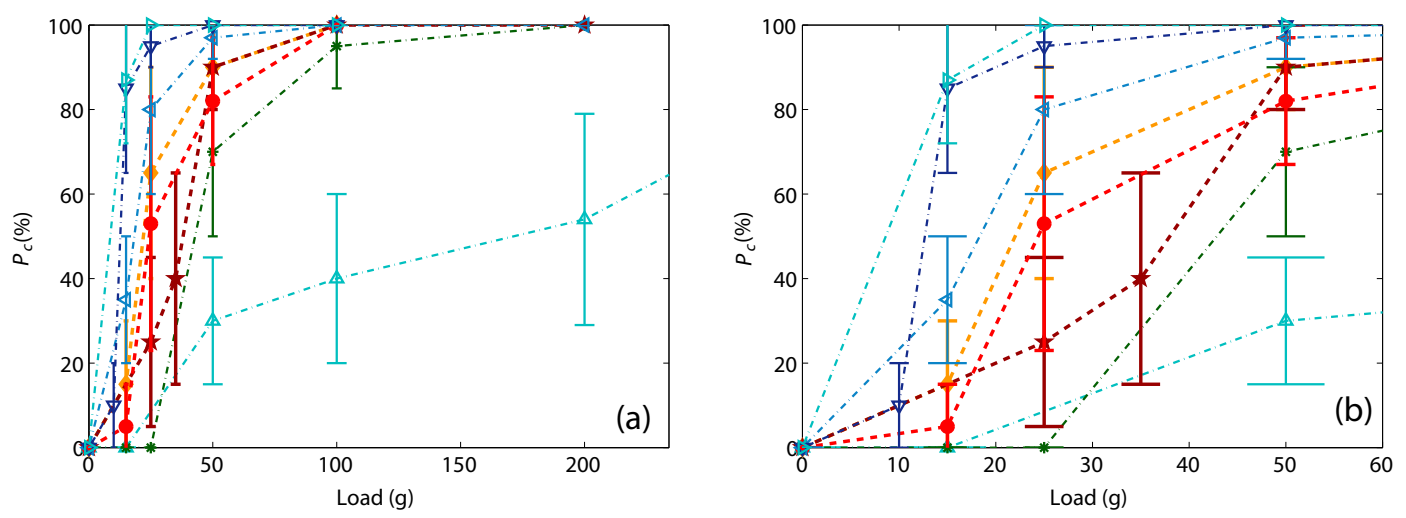

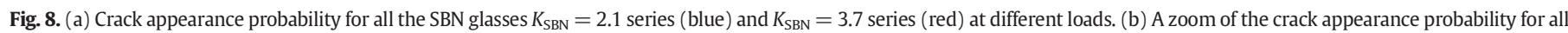
the SBN glasses $K_{\mathrm{SBN}}=2.1$ series (blue) and $K_{\mathrm{SBN}}=3.7$ series (red) for loads between $0 \mathrm{~g}$ and $50 \mathrm{~g}$. 


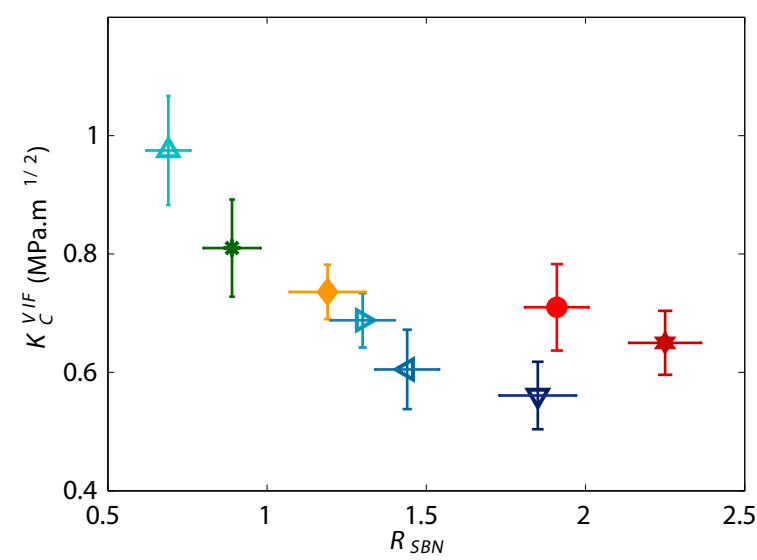

Fig. 9. Toughness values $K_{C}^{V I F}$ of SBN glasses depending on $R_{\mathrm{SBN}}$ for $K_{\mathrm{SBN}} \sim 2.5$ series (blue) and $K_{\mathrm{SBN}} \sim 4.5$ series (red).

Post-treatment of the images reveals $d_{a}, P_{a d}, V_{a}^{-}$and $V_{a}^{+}$(Fig. 1). Table 2 presents these parameters. The densified volume is then estimated through the recovered volume ratio $\left(V_{R}\right)$ of the indent below the surface:

$V_{R}=\frac{\left(V_{i}^{-}-V_{a}^{-}\right)+\left(V_{a}^{+}-V_{i}^{+}\right)}{V_{i}^{-}}$.

\subsubsection{Shear flow}

Shear flow represents a plastic flow generating a displacement of matter without volume change. The pile-up around the indents exposes the amount of shear flow. Profiles extracted from Fig. 1 follow the dotted blue line. Sellappan et al. [18] propose $V_{P}$ to study the volumeconserving flow ratio:

$V_{P}=\frac{\left(2 V_{i}^{+}-V_{a}^{+}\right)}{V_{i}^{-}}$

$\left(V_{a}^{+}-V_{i}^{+}\right)$represents the densified volume contribution in the pile-up area. The denominator in Eq. (9) normalizes the shear flow.

\section{Results}

This section details the structural and mechanical property investigations. First, this section presents results concerning the structural

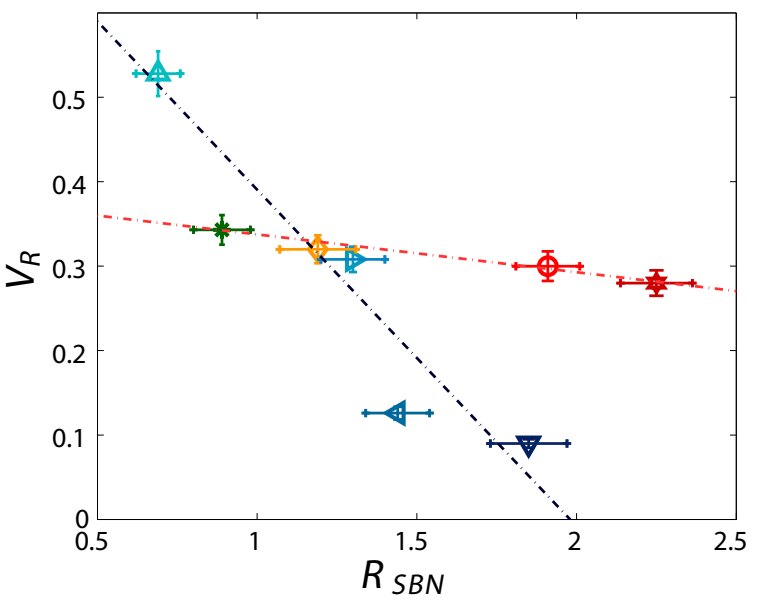

Fig. 10. The recovery volume decreases with $R_{\mathrm{SBN}}$. Yet, the slopes $\left(m_{K_{\mathrm{SBN}} \sim 2.5}=-0.4\right.$ and $m_{K_{\text {SBN }} \sim 4.5}=-0.04$ ) depend significantly on $K_{\mathrm{SBN}}$.

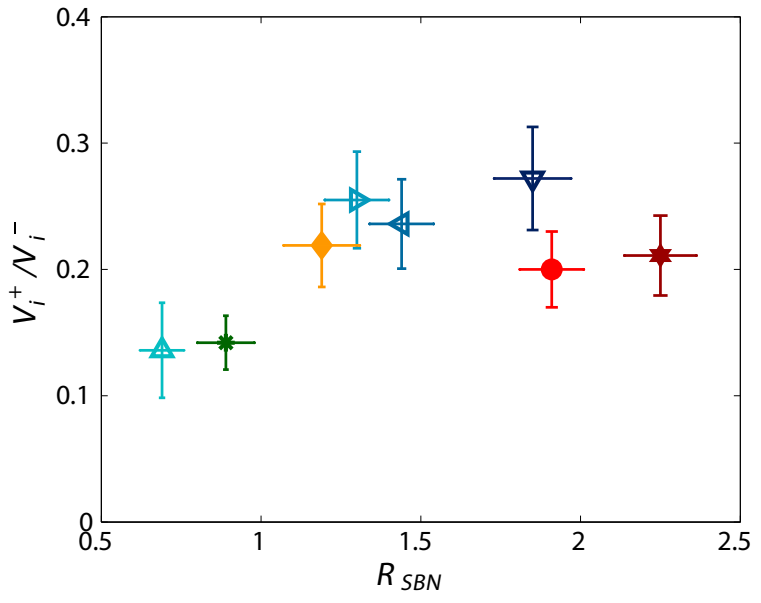

Fig. 11. The normalized ratio $\left(V_{i}^{+} / V_{i}^{-}\right)$of the glasses pile-up with $R_{\mathrm{SBN}}$ displays two trends depending on $K_{\mathrm{SBN}}$. For $K_{\mathrm{SBN}} \sim 2.5$, the ratio increases initially then appears to stabilize. For $K_{\mathrm{SBN}} \sim 4.5$, the ratio decreases slightly.

properties of SBN glasses. Following this, the section provides results concerning the indentation. The end of the section presents the variations of $V_{R}$ and $V_{P}$.

\subsection{Structural investigation}

\subsubsection{Density, $\rho$}

Archimedes' principle gives the density, $\rho$, for the different glasses. Fig. 3 shows how $\rho$ varies with $R_{\mathrm{SBN}}=\frac{\left[\mathrm{Na}_{2} \mathrm{O}\right]}{\left.\mathrm{B}_{2} \mathrm{O}_{3}\right]}$ (where $[\cdot] \equiv$ mol\%). Previous literature details a complex 3D analysis concerning density's dependence on $K_{\mathrm{SBN}}=\frac{\left[\mathrm{SiO}_{2}\right]}{\left[\mathrm{B}_{2} \mathrm{O}_{3}\right]}$ and $R_{\mathrm{SBN}}[19,42-44]$. When possible the same batches of glasses were used herein as in the Barlet et al. [19] study.

\subsubsection{Elastic moduli, E and $\nu$}

As mentioned in Subsection 2.2.2, E and $\nu$ result from both measurements of the longitudinal wave $\left(V_{L}\right)$ and of the transverse wave $\left(V_{T}\right)$ speeds. Appendix B contains these raw measurements. Eqs. (2) and (3) give way to the estimates of $E$ and $\nu$. Table 1 presents the results of $E$ and $\nu$. Clearly $E$ and $\nu$ depend on the chemical composition of the SBN glasses. Conversely, $E$ and $\nu$ do not vary monotonically with $R_{\mathrm{SBN}}$.

\subsection{3. ${ }^{11} B$ MAS NMR}

Table 1 presents results on the amount of ${ }^{[4]} \mathrm{B}$ in each SBN sample. The chemical composition of silicate glasses significantly affects the ${ }^{[4]}$ B count $[45,46]$.

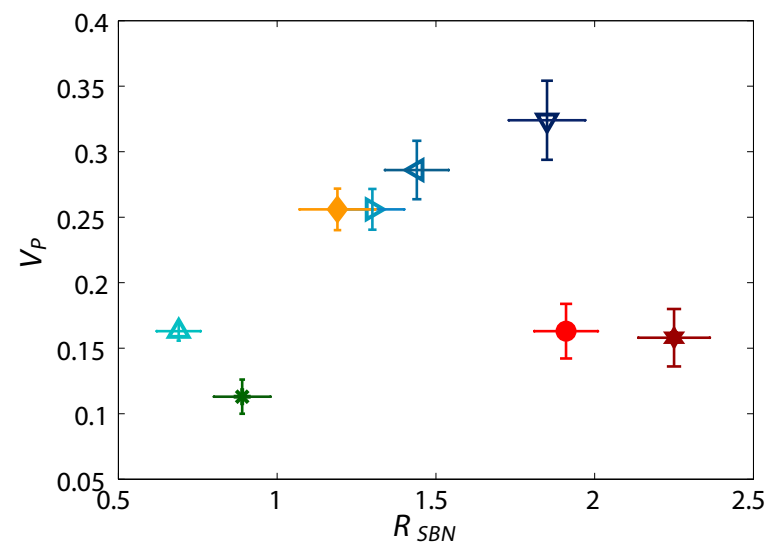

Fig. 12. The pile-up ratio $\left(V_{P}\right)$ which is related to the volume-conserving shear flow as a function of $R_{\mathrm{SBN}}$. The tendencies differ for approximately constant $K_{\mathrm{SBN}}$. 

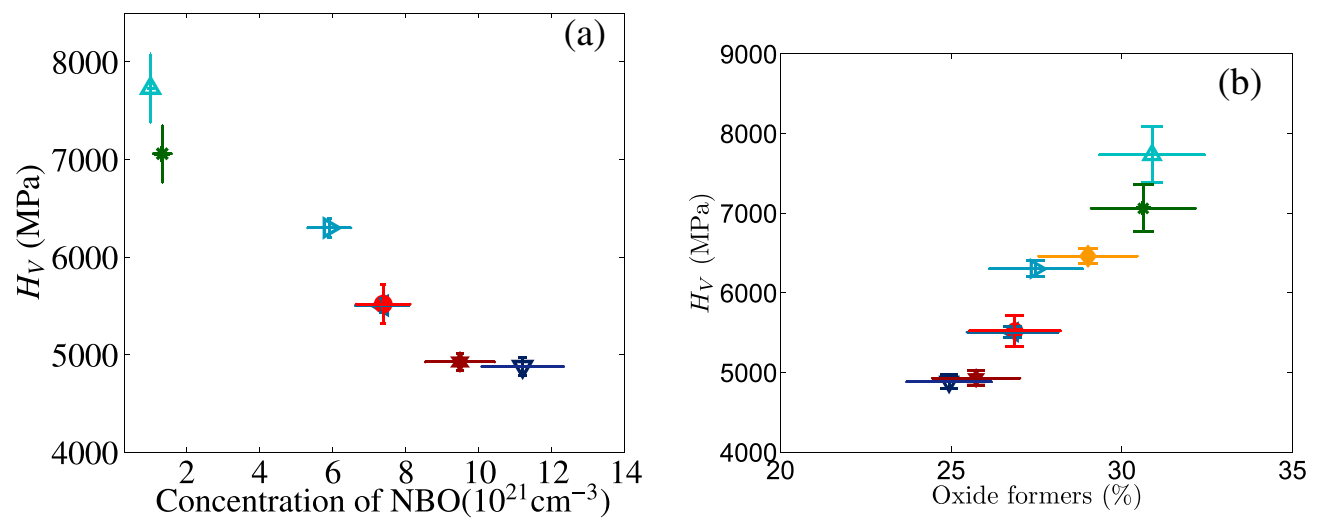

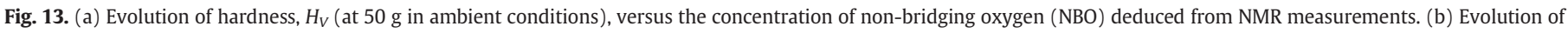
hardness, $H_{V}$ (at $50 \mathrm{~g}$ in ambient conditions), versus percentage of oxide formers determined from ICP measurements.

\subsection{Mechanical testing results}

Immediately after unloading the Vickers' indenter, an optical microscope coupled with the Vickers's indenter visually captures the features of the indents. Fig. 4 displays indentation imprints for the $K_{\mathrm{SBN}} \sim 2.5$ series (from left to right: SBN 12, SBN 25, SBN 30, and SBN 35). A clear discrepancy appears according to the crack behavior. For low amounts of sodium (i.e. SBN 12) at $50 \mathrm{~g}$, no cracking occurs. On the other hand, cracks emerge at the surface in glasses with higher sodium content. In addition, the light reflection seen in SBN 35 glass can be a sign of pile-up.

Fig. 5 displays indentation prints for the $K_{\mathrm{SBN}} \sim 2.5$ series (from left to right: SBN 12, SBN 25, SBN 30, and SBN 35) at $50 \mathrm{~g}$ in ambient conditions via an AFM. Subsequently, these AFM images aid in enumerating $P_{i d}, d_{i}$, $V_{i}^{-}$and $V_{i}^{+}$Table 2 presents the average results of at least 10 different indents.

\subsubsection{Hardness, $H_{V}$}

Knowing the maximum load applied $(P=50 \mathrm{~g})$ during the indent along with $d_{i}$, Eq. (5) gives $H_{V}$ for each sample. $H_{V}$ results herein represent the average of at least 10 tests. Table 2 presents the obtained values. Fig. 6 presents the evolution of $H_{V}(\mathrm{MPa})$ as a function of $R_{\mathrm{SBN}}$. The chemical composition of silicate glasses significantly affects the hardness values. For constant $K_{\mathrm{SBN}}=\frac{\left[\mathrm{SiO}_{2}\right]}{\left[\mathrm{B}_{2} \mathrm{O}_{3}\right]}$ and increasing $R_{\mathrm{SBN}}$, the hardness values decrease. The decrease is less pronounced for

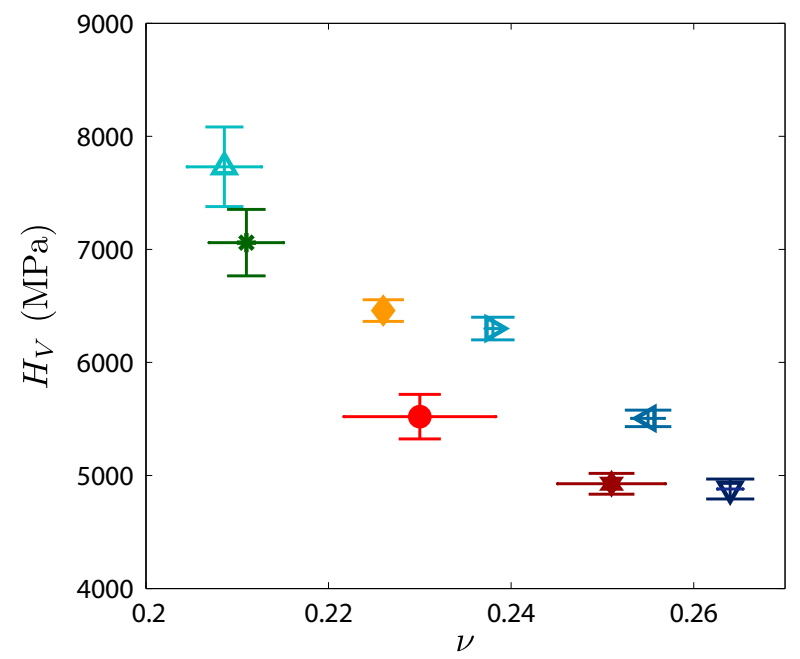

Fig. 14. Evolution of hardness values as a function of the Poisson ratio $(\nu)$ (indentation at $50 \mathrm{~g}$ in ambient conditions).
$K_{\mathrm{SBN}} \sim 4.5$ (i.e. samples with more $\mathrm{SiO}_{2}$ ). This decrease in $H_{V}$ corresponds to an increasing residual penetration depth $\left(P_{i d}\right)$ as determined from AFM imaging (see Table 2). As the sodium content increases, the indenter penetrates deeper into the glass.

\subsubsection{Crack resistance}

Fig. 7 displays optical images of SBN 14 at different loads. As seen in the figure, at low loads ( $P \leq 25 \mathrm{~g}$ ) cracks do not propagate off the corners of the Vickers's indenter. The average number of cracks initiating off the corners of the Vickers' indenter increases between $25 \mathrm{~g}$ and $200 \mathrm{~g}$. At $200 \mathrm{~g}$, all four corners have, on average, one crack.

The probability of crack appearance, $P_{C}$, is the average number of cracks per corner out of at least 10 indents at a given load. Fig. 8 exemplifies the probability of crack appearance in SBN 14 (dark green stars) along with the other SBN samples. All SBN glasses, except SBN 12 , rapidly increase their crack appearance probability at low loads. $100 \% P_{C}$ never occurred for SBN 12 due to limitations of the experimental setup (i.e. higher loads were not feasible with the hardness tester).

As stated in the previous section the crack resistance, $C_{R}$, is the load at which the probability of crack appearance equals $50 \%$ (estimated by looking at when the data in Fig. 8 crosses the $50 \%$ line). Table 2 presents $C_{R}$ for the different SBN samples. SBN 12 is significantly different from the other glasses.

\subsubsection{Indentation fracture toughness, $K_{C}^{V I F}$}

Section 2.3.6 details the requirements for radial/median cracks (i.e. $c>1.25 d$ ). The formation of radial/median cracks permits the use of Evans and Marshall's model. On the other hand, to compare the $K_{C}^{V I F}$ values in the different glasses, the maximum load needs to be the same in all glasses. For almost all the samples, reasonable indentation imprints plus sufficient energy to propagate medial/radial cracks $\left(C_{R}>50 \%\right.$ ) occur at $50 \mathrm{~g}$. The only exception herein is SBN 12 , which neither forms well-developed cracks nor satisfies the criterion $c>1.25 \mathrm{~d}$ at $50 \mathrm{~g}$. Hence, Evans and Marshall's model applies well to all samples but SBN 12. On the other hand, comparing and contrasting $K_{C}^{V I F}$ results estimated through different models also lead to discrepancies. Thus, results herein all use the Evans and Marshall's model, but care should be taken when examining SBN 12 results.

Fig. 9 shows that $K_{C}^{V I F}$ decreases as the sodium content increases for constant $K_{\mathrm{SBN}}$. It should be noted that $K_{C}^{\mathrm{VIF}}$ for SBN 12 probably overestimates the correct value due to the lack of well-developed cracks.

\subsection{Complementary measurements of Vickers' indentations}

The high pressure under the indenter can cause material compaction $[2-4,7,14]$. The original structural configuration can be recovered if sufficient activation energy is supplied to the material (for instance by heating) as demonstrated by Bridgman and Simon [38] and later by 

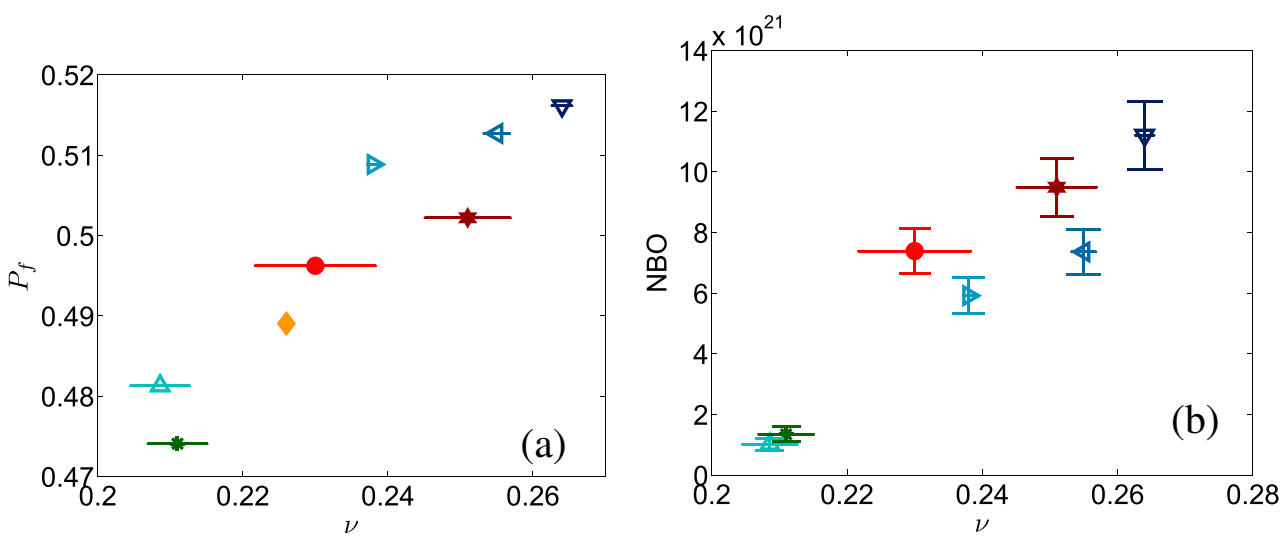

Fig. 15. (a) Evolution of glass packing density $\left(P_{f}\right)$ versus the Poisson's ratio $(\nu)$; (b) evolution of the concentration of NBO from NMR measurements as a function of $\nu$.

Mackenzie [15]. Table 2 presents parameters acquired from AFM images before $\left(d_{i}, P_{i d}, V_{i}^{-}\right.$and $\left.V_{i}^{+}\right)$and after $\left(d_{a}, P_{a d}, V_{a}^{-}\right.$and $\left.V_{a}^{+}\right)$annealing. These values are the average values of at least ten indents. $V_{R}$ from Eq. (8) provides a means to calculate the amount of volume recovered due to annealing. This indicates the amount of densification due to an indenter. Table 2 reveals the average $V_{R}$ for the various SBN samples. It is well noted that annealing may not relieve all regions of densified material due to geometrical constraints. In $K_{\mathrm{SBN}} \sim 4.5$ the residual stress field can lead to the development of cracks during unloading [18]. Confirming this hypothesis requires further studies.

Fig. 10 unveils two scenarios depending on the value of $K_{\mathrm{SBN}}$. For samples with low $K_{\mathrm{SBN}}$ values, the recovery volume decreases roughly linearly with $R_{\mathrm{SBN}}$. ( $V_{R}=m_{K_{\mathrm{SBN}} \sim 2.5} R_{S B N}+b_{\mathrm{K}_{\mathrm{SBN}} \sim 2.5}$ where $m_{K_{S B N} \sim 2.5}=-0.409 \pm 0.005$ and $\left.b_{K_{S B N} \sim 2.5}=0.80 \pm 0.002\right)$. On the other hand, the $K_{\mathrm{SBN}} \sim 4.6$ series exhibits a significantly less pronounced decrease but approximately linearly $\left(V_{R}=m_{K_{S B N} \sim 4.6} R_{S B N}+b_{K_{S B N} \sim 4.6}\right.$ where $m_{K_{S B N} \sim 4.5}=-0.0431 \pm 0.003$ and $\left.b_{K_{S B N} \sim 4.6}=0.38 \pm 0.005\right)$.

In addition to densification processes, pile-up occurs. The glasses' pile-up $\left(V_{i}^{+}\right)$response depends on the chemistry of the glass. Fig. 11 presents the normalized ratio $\left(V_{i}^{+} / V_{i}^{-}\right)$of the pile-up as a function of $R_{\mathrm{SBN}}$. Variations in $\left(V_{i}^{+} / V_{i}^{-}\right)$convey the glass's tendency to pile-up around the indenter under pressure [47]. Fig. 11 unveils two different scenarios depending on the value of $K_{\mathrm{SBN}}$. For $K_{\mathrm{SBN}} \sim 2.5$, the ratio

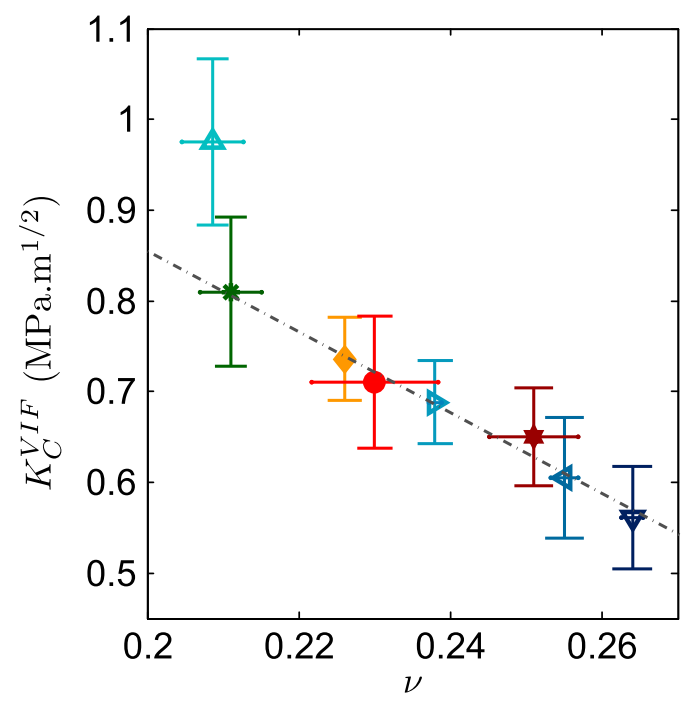

Fig. 16. Toughness values $\left(K_{C}^{V I F}\right)$ of all SBN glasses as a function of $\nu$. The line $\left(K_{C}^{V I F}=\right.$ $m v+b$ where $m=-4.46 \pm 0.27$ and $b=1.75 \pm 0.06$ ) depicts a liner fit through all of the data excluding SBN 12. initially increases and subsequently stabilizes. For $K_{\mathrm{SBN}} \sim 4.5$, the ratio decreases, and then remains stable within the error bars. There is a chance that it too increases; however, determining this requires smaller $R_{\mathrm{SBN}}$ values.

Within the pile-up region, there is a chance that densification occurs. Eq. (9) permits the removal of the densified portion of the pile-up by imaging before and after annealing. Annealing relieves densified areas this highlighting variations in isochoric shear flow. Fig. 12 depicts how $V_{P}$ varies with $R_{\mathrm{SBN}}$ for the different series of glasses. For $K_{\mathrm{SBN}} \sim 2.5$, the ratio increases; yet, for $K_{\mathrm{SBN}} \sim 4.6$, the ratio decreases.

A possible explanation as to why SBN 55 and SBN 59 decrease is that annealing may not fully relieve densified regions, and it may also induced some plastic flow. Confirming this hypothesis requires more research.

\section{Discussion}

The experimental observations reported in the previous section can be qualitatively understood by invoking Dell and Bray's scenario $[43,45]$. SBN glasses with a low concentration of sodium ions $\left(R_{\mathrm{SBN}}<R_{\max }^{\mathrm{SBN}}=\right.$ $0.5+K_{\mathrm{SBN}} / 16$ ) consist predominantly of oxide formers ( $\mathrm{Si}$ and $\mathrm{B}$ atoms). The small amount of $\mathrm{Na}^{+}$available in the glass transforms fully coordinated ${ }^{[3]} \mathrm{B}$ into fully coordinated ${ }^{[4]} \mathrm{B}[43,45]$. When $R_{\mathrm{SBN}}>R_{\max }$, the extra $\mathrm{Na}^{+}$begins to form NBOs initially in the $\mathrm{Si}$ network and then in the $\mathrm{B}$ network. A side effect to the formation of the NBOs is the reversal of fully coordinated ${ }^{[4]} \mathrm{B}$ units to ${ }^{[3]} \mathrm{B}$ units with at least one NBO. Table 1 confirms the decrease in ${ }^{[4]} \mathrm{B}$ units as $\left[\mathrm{Na}_{2} \mathrm{O}\right]$ increases (or as $R_{\mathrm{SBN}}$ increases for constant $K_{\mathrm{SBN}}$ ).

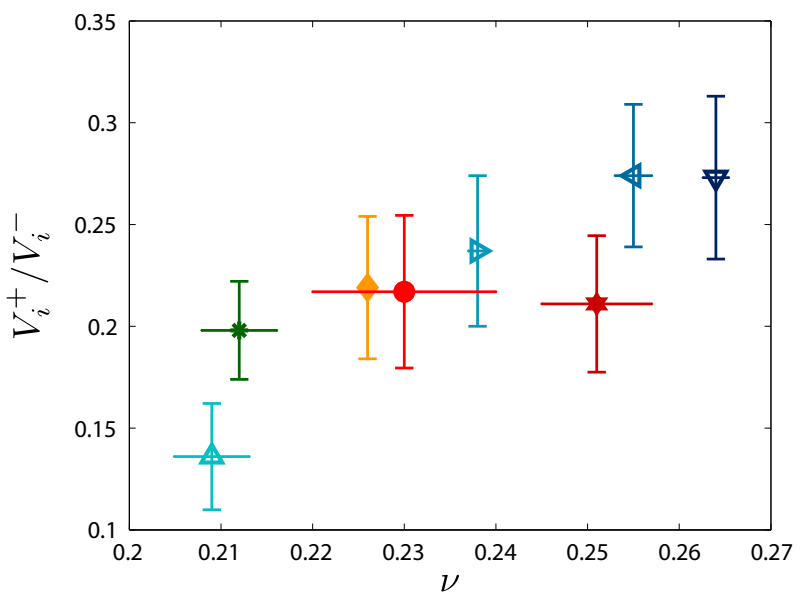

Fig. 17. $\frac{V_{i}^{+}}{V_{i}^{+}}$versus $\nu$ before annealing the sample. 

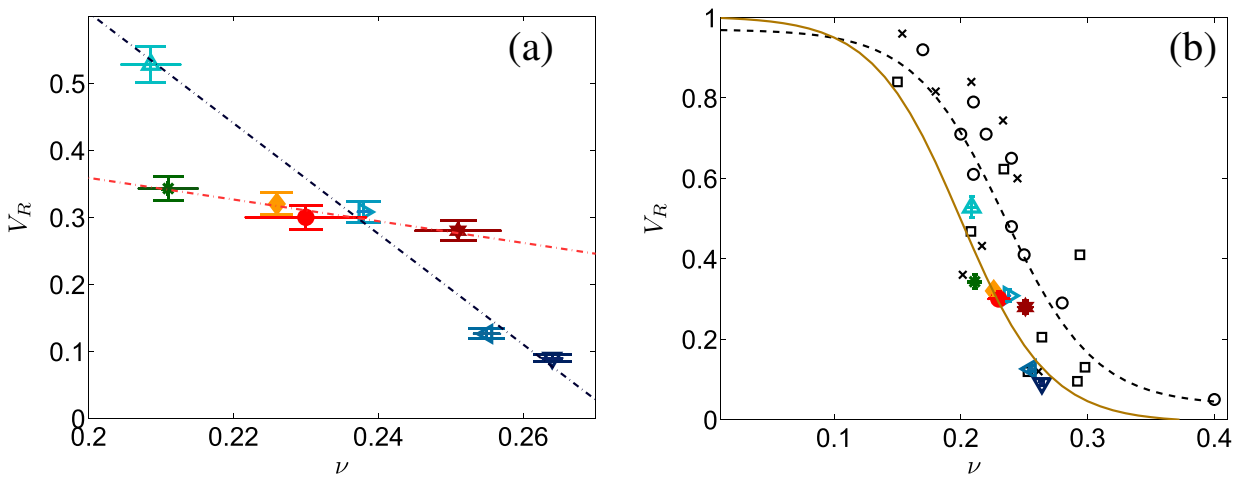

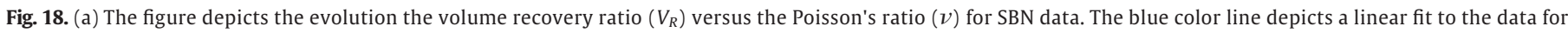

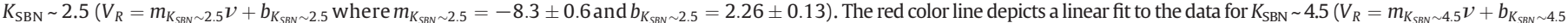

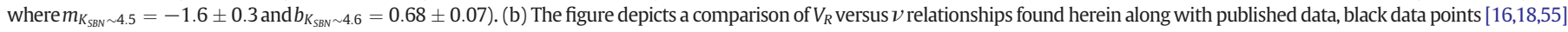

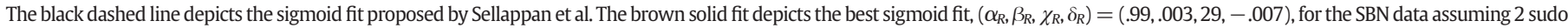
points: $(0,1)$ and $(.5,0)$

\subsection{Linking hardness $\left(H_{V}\right)$ to the glass structure}

The results in Section 3.2.1 reveal a decrease in the hardness of the SBN glass as $R_{\mathrm{SBN}}$ increases (Fig. 6). Linking this variation to the structure is the key in understanding the glasses' behavior. High levels of $\left[\mathrm{Na}_{2} \mathrm{O}\right]$ reduce the SBN glasses resistance to Vickers's indentation and forms NBO on the network formers when $R_{\mathrm{SBN}}>R_{\max }$. This displays an inverse correlation between $H_{V}$ and NBO in the glassy network (Fig. 13).

NBO reduces the connectivity of the glass, which in turn alters the short- and medium-range order. Poisson's ratio $(\nu)$ provides an interesting insight into the glass's short- and medium-range order. The Poisson's ratio is the negative of the ratio between the tensile and lateral strain. The SBN glasses presented herein exhibit a range of values from 0.21 to 0.27 (Table 1 ). $H_{V}$ decreases almost linearly with $\nu$ (Fig. 14). When $\nu$ is low (i.e. the glass network is reticulate), $H_{V}$ is high.

As stated above, additional $\left[\mathrm{Na}_{2} \mathrm{O}\right]$ alters both the number of NBOs and $\nu$. Moreover, the NBOs concentration is linearly linked to $\nu$. It also affects the packing fraction $\left(P_{f}\right)$ which is a measure of how densely the system is packed $[48,49]$. The ratio between the minimal theoretical density $\left(\rho_{t}\right)$ and the actual density of the glass $(\rho)$ gives $P_{f}$ :

$P_{f}=\frac{\rho}{\rho_{t}}$ where

$$
\rho_{t}=\frac{M}{V}=\frac{\sum_{i=1}^{n}\left(f_{i} M_{i}\right)}{\sum_{i=1}^{n}\left(f_{i} V_{i}\right)} .
$$

Here, the sums occur over the different oxides in the systems. $f_{i}$ is the molar fraction of each oxide. For oxide $\left[\mathrm{A}_{\mathrm{x}} \mathrm{O}_{\mathrm{y}}\right]$, the ideal volume is [50]:

$V_{i}=\frac{4 \pi N_{A}}{3}\left(x r_{A}^{3}+y r_{O}^{3}\right)$

$N_{A}$ is Avogadro number. $r_{A}$ and $r_{O}$ are the ionic radii of the cation and anion oxides respectively. Fig. 15 reveals $P_{f}$ increases as $\nu$ increases. For low $\left[\mathrm{Na}_{2} \mathrm{O}\right]$ concentrations and $\nu$, the glass structure has a large fraction of free volume (i.e. low glass packing density). On the other hand, increasing the $\left[\mathrm{Na}_{2} \mathrm{O}\right]$ concentrations gives higher $\nu$ and high $P_{f}$; consequently the free volume decreases in these glass structures. Moreover, $H_{V}$ decreases.

Thus, it appears that the atomic bond strength and the reticulation of the glassy network control the behavior upon indentation. These results corroborate Kilymis et al. recent studies on similar glasses. MD simulations on similar glasses reveal that $H_{V}$ decreases as the number of ${ }^{[3]} \mathrm{B}$ and NBOs increases, as observed here [51,52].

$H_{V}$ sheds light on a material's resistance to permanent deformation. Yet, two glasses with the same $H_{V}$ may exhibit significantly different overall behaviors upon indentation: resistance to cracking, pile-up, etc. The subsequent parts of this section address these differences.
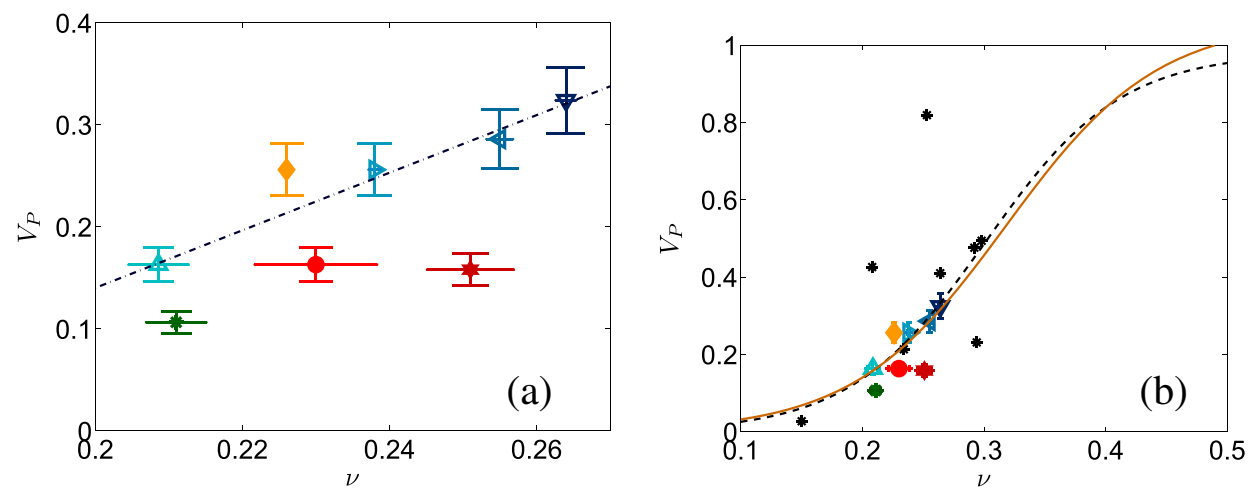

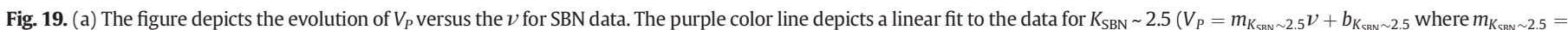

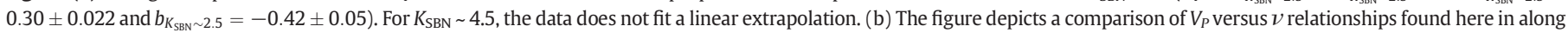

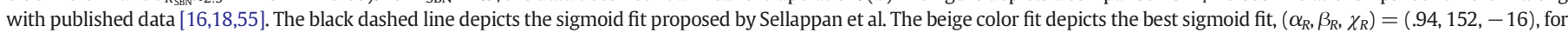
the SBN data herein assuming 2 sudo points: $(0,0)$ and $(.5,1)$. 


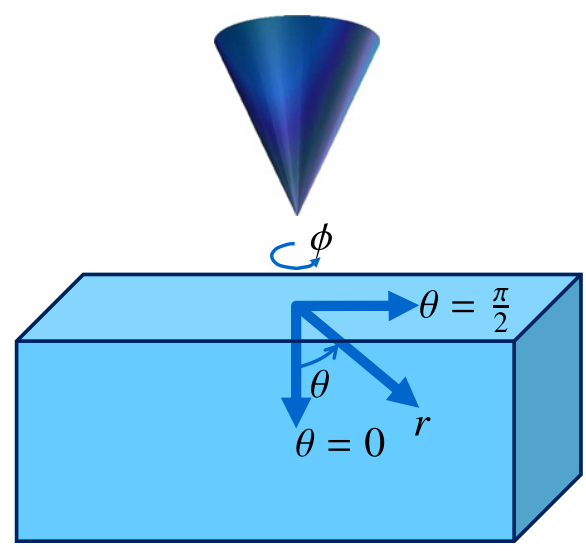

Fig. 20. Depicts spherical polar coordinates $(r, \theta, \phi)$ used in Yoffe's stress field equations for a conic indenter [56].

\subsection{Linking the resistance to cracking $C_{R}$ to the glass structure}

As observed in Fig. 8, the $C_{R}$ value for SBN 12 is significantly higher than $C_{R}$ for other SBN glasses. Table 2 provides $C_{R}$ values for the SBN series. Crack appearance depends on how the glass deforms under the indenter. Processes occurring during indentation do not favor growth of median/radial cracks in SBN 12 as observed for other SBN glasses. Thus, complex processes such as densification and shear flow are non-negligible for $C_{R}$ estimates. Section 4.4 examines densification and shear flow processes under the indenter.

\subsection{Linking the indentation fracture toughness, $K_{C}^{V I F}$, to the glass structure}

Over the past several decades, Evans and Marshall's model (Eq. (7)) and other models provided a method to estimate the indentation fracture toughness of brittle materials (especially ceramics). Yet, these techniques are essentially linked to the occurrence of a plastic zone beneath the contact area and isochoric deformation. Figs. 10, 11, and 12 all reveal varying deformation mechanisms in the SBN ternary systems as the composition changes. This calls for caution in interpreting indentation cracking patterns. Nevertheless, in the absence of a better indentation tool to probe the cracking resistance, Evans and Marshall's model (Eq. (7)) can be used for comparison purposes.

Through Evans and Marshall's model, Vickers's indentation provides a method to estimate $K_{C}^{V I F}$. Fig. 9 reveals a decreasing trend of $K_{C}^{V I F}$ with $R_{\mathrm{SBN}}$. Yet, the trend depends on the $K_{\mathrm{SBN}}$ series, which implies that the underline structure of the glass should play an important role. Conversely, the variations of $K_{C}^{V I F}$ with $\nu$, plotted in Fig. 16 reveal a fairly good collapse. A notable exception is SBN 12, which as already mentioned in Section 3, does not develop well defined cracks. Densification under the indenter is a possible source of the discrepancy (to be studied in Section 4.4). Otherwise, Fig. 16 reveals $K_{C}^{V I F}$ decreases linearly with $\nu$ $\left(K_{C}^{V I F}=m \nu+b\right.$ where $m=-4.46 \pm 0.27$ and $\left.b=1.75 \pm 0.06\right)$.

\section{Table 3}

Sellappan et al. [18] proposed these parameters for Yoffe's stress field. B is the strength of the Blister field; and $\beta$ is Sellappan's blister field strength. $V_{i}{ }^{m}$ is an estimate of the indent volume disregarding elastic recover from assumptions made by [18]. $a$ is an estimate of the half diagonal of the projected surface area of an indent, $\Psi$ is the angle of the indenter.

\begin{tabular}{lll}
\hline Variable & symbol & function \\
\hline Strength of blister field & $\mathrm{B}$ & $\frac{3 E}{4 \pi(1-2 v)(1+\nu)} \beta V_{i}{ }^{m}$ \\
Sellappan's blister field strength & $\beta$ & $\left(1-V_{R}-V_{P}\right)$ \\
Volume of indent disregarding elastic recovery & $V_{i}{ }^{m}$ & $\frac{2 a^{3}}{3 \tan (\Psi)}$ \\
half the diagonal of the projected surface area & $a$ & $\left(\frac{P}{2 H}\right)^{0.5}$ \\
apical angle of the indenter & $\Psi$ & 70.3
\end{tabular}

Table 4

Table of predominate opening mode cracks due to a conic indenter and their corresponding stresses $[56,18]$. Stresses are normalized by the $H$ of a conical indenter.

\begin{tabular}{lclll}
\hline Type of crack & Driving stress field & $\theta$ & Boussinesq term & Blister term \\
\hline Ring & $\sigma_{r r} / H$ & $\pi / 2$ & $0.5-\nu$ & $\frac{2(\nu-2) \beta}{\pi(1+\nu)(1-2 \nu) \tan (\Psi)} \frac{E}{H}$ \\
Radial & $\sigma_{\phi \phi} / H$ & $\pi / 2$ & $\nu-0.5$ & $\frac{2 \beta}{\pi(1+\nu) \tan (\Psi) \frac{E}{H}}$ \\
Median & $\sigma_{\theta \theta} / H$ & 0 & $0.25-0.5 \nu$ & $-\frac{\beta}{\pi(1+\nu) \tan (\Psi)} \frac{E}{H}$ \\
Lateral & $\sigma_{r r} / H$ & 0 & -1.5 & $\frac{6 \beta}{\pi(1+\nu)(1-2 \nu) \tan (\Psi)} \frac{E}{H}$ \\
\hline
\end{tabular}

4.4. Contribution of densification and shear flow to the permanent deformation

Beyond $H_{V}$ and $K_{C}^{V I F}$, information on the processes occurring during indentations can be extracted from analyzing post-indentation AFM images. For example a good correlation is found between $V_{i}^{+} / V_{i}^{-}$and $\nu$ (Fig. 17). This shows that pile-up processes favor glasses with a lower degree of polymerization.

Current literature suggests that the chemical composition impacts more $V_{R}$ than $H_{V}[16,17,53,54]$. Sellappan et al. [18] evidenced a sigmoid relation between $\nu$ and $V_{R}$. As $\nu$ increases $V_{R}$ decreases, thus the contribution of densification occurring in the system decreases.

Fig. 18 unveils two different scenarios when looking at approximately constant $K_{\mathrm{SBN}}$. For samples with $K_{\mathrm{SBN}} \sim 2.5$, the recovery volume decreases with $\nu\left(V_{R}=m_{K_{S B N} \sim 2.5} \nu+b_{K_{S B N} \sim 2.5}\right.$ where $m_{K_{S B N} \sim 2.5}=$ $-8.3 \pm 0.6$ and $\left.b_{K_{S B N} \sim 2.5}=2.26 \pm 0.13\right)$. As the sodium content increases for low $K_{\mathrm{SBN}} \sim 2.5, V_{R}$ decreases quickly. On the other hand, the $K_{\mathrm{SBN}} \sim 4.5$ series exhibits a significantly less pronounced decrease $\left(V_{R}=m_{K_{\mathrm{SBN}} \sim 4.5} \nu+b_{K_{\mathrm{SBN}} \sim 4.5}\right.$ where $m_{K_{\mathrm{SBN}} \sim 4.5}=-1.6 \pm 0.3$ and $b_{K_{\mathrm{SBN}} \sim 4.6}=$ $0.68 \pm 0.07$ ).

Nevertheless, Sellappan et al. attempted to develop a universal behavior for $V_{R}$ with $\nu$ [18]. Fig. 18 presents the data collected herein, their data, and their sigmoid fit (dash black line):

$$
V_{R}=\frac{1}{\alpha_{R}+\beta_{R} \exp \left(\chi_{R} \nu\right)}+\delta_{R}
$$

where $\left(\alpha_{R}, \beta_{R}, \chi_{R}, \delta_{R}\right)$ are fitting parameters. The data for the SBN glasses does fit the spread of data presented in Sellappan et al. [18]. Yet, it has a tendency to be shifted left (i.e. smaller values of $\nu$ ) as compared to the glasses of Sellappan et al. A better fit (solid brown line in Fig. 18) for the SBN glasses would occur with $\left(\alpha_{R}, \beta_{R}, \chi_{R}, \delta_{R}\right)=(.99, .003,29,-.007)$.

Understanding shear flow requires $V_{P}$. Sellappan et al. [18] evidenced a sigmoid increasing trend between $\nu$ and $V_{P}$. Thus the amount of volume-conserving shear flow increases with $\nu$. Fig. 19 (left) unveils two different scenarios when looking at approximately constant $K_{\mathrm{SBN}}$. For samples with $K_{\mathrm{SBN}} \sim 2.5, V_{P}$ increases with $\nu\left(V_{P}=\right.$ $m_{K_{S B N} \sim 2.5} \nu+b_{K_{S B N} \sim 2.5}$ where $m_{K_{S B N} \sim 2.5}=0.30 \pm 0.022$ and $b_{K_{S B N} \sim 2.5}=-$ $0.42 \pm 0.05)$. On the other hand, the $K_{\mathrm{SBN}} \sim 4.5$ series exhibits a drastic decrease in $V_{P}$ with $\nu$. Sellappan et al. attempted to universalize the behavior of $V_{P}$ as they did with $V_{P}$ [18]. In doing this, they concentrated on the pile-up. Fig. 19 presents the data collected herein, their data (black point), and their sigmoid fit (dash black line):

$V_{P}=\frac{1}{\alpha_{P}+\beta_{P} \exp \left(\chi_{P} \nu\right)}$

where $\left(\alpha_{P}, \beta_{P}, \chi_{P}\right)$ are fitting parameters. The data for the SBN glasses does fit the spread of data presented in Sellappan et al. [18]. A better fit for the SBN glasses would occur with $\left(\alpha_{P}, \beta_{P}, \chi_{P}\right)=(.94,152,-16)$.

SBN glasses do fit the general spread of data when considering previously published $V_{P}$ verse $\nu$ data. On the other hand, a sigmoid fit misses the subtleties of the SBN glasses for constant $K_{\mathrm{SBN}}$. Moreover, it is difficult to understand why the trends of $V_{P}$ are so drastically different: $K_{\mathrm{SBN}} \sim 2.5$ has a tendency to increase and $K_{\mathrm{SBN}} \sim 4.5$ has a tendency to decrease. Understanding this requires more research. 

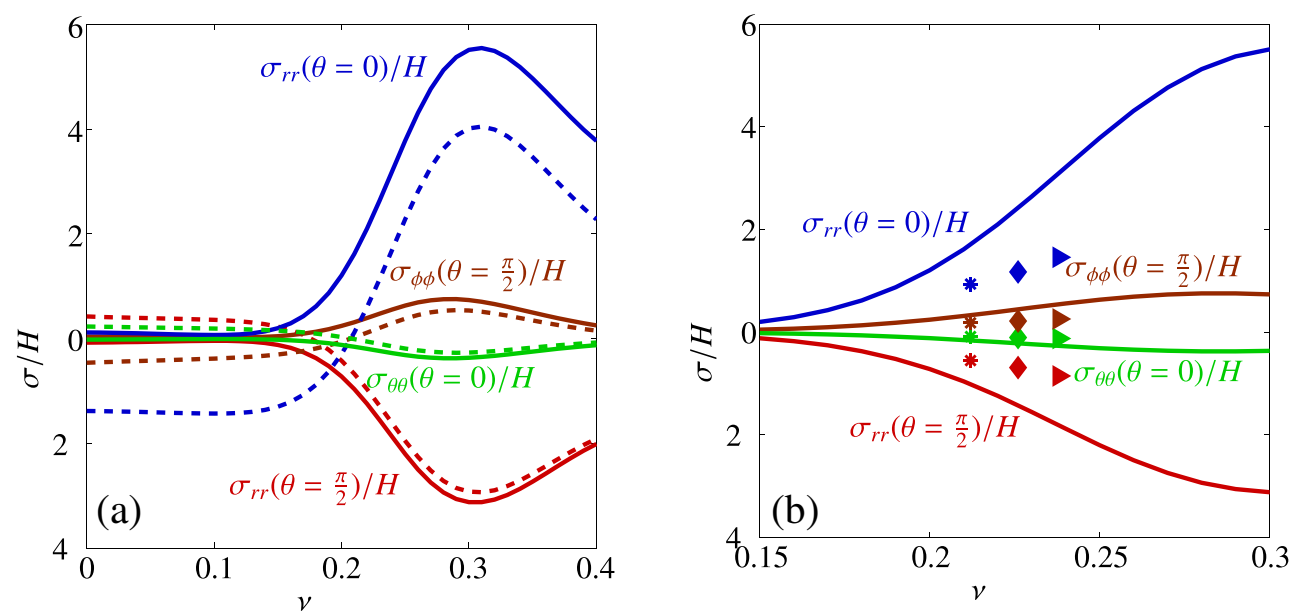

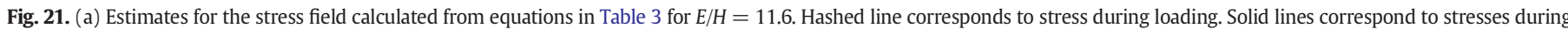

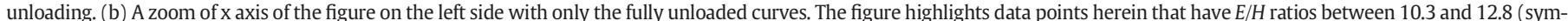

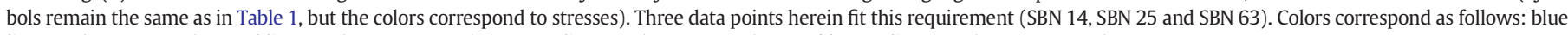
lines $\sigma_{r r}(\mathrm{r}=\mathrm{a}, \theta=0) / H$; red lines $\sigma_{r r}(\mathrm{r}=\mathrm{a}, \theta=\pi / 2) / H$; green lines $\sigma_{\theta \theta}(\mathrm{r}=\mathrm{a}, \theta=0) / H$; and brown lines $\sigma_{\phi \phi}(\mathrm{r}=\mathrm{a}, \theta=\pi / 2) / H$.

\subsection{Residual stresses}

Upon indentation, the indenter subjects a small region beneath itself to elastic/plastic processes [12]. Yet, sufficiently far from the indent, the material obeys linear elastic dynamics. Assuming a conical indenter for symmetry purposes and to reduce the problems arising due to edges, Yoffe estimates the stresses induced during loading and unloading via Boussinesq and blister fields in spherical polar coordinates $(r, \theta, \phi)$, see Fig. 20 [56]. The following equations (with Table 3 for parameters) present Yoffe's stress fields:

$\sigma_{r r}=\frac{P}{2 \pi r^{2}}[1-2 \nu-2(2-\nu) \cos \theta]+\frac{4 B}{r^{3}}\left[(5-\nu) \cos ^{2} \theta-2+\nu\right]$

$\sigma_{\theta \theta}=\frac{P(1-2 \nu) \cos ^{2} \theta}{2 \pi r^{2}(1+\cos \theta)}-\frac{2 B}{r^{3}}(1-2 \nu) \cos ^{2} \theta$

$\sigma_{\phi \phi}=\frac{P(1-2 \nu)}{2 \pi r^{2}}\left[\cos \theta-\frac{1}{1+\cos \theta}\right]-\frac{2 B}{r^{3}}(1-2 \nu)\left(2-3 \cos ^{2} \theta\right)$

$\sigma_{r \theta}=\frac{P(1-2 \nu) \sin \theta \cos \theta}{2 \pi r^{2}(1+\cos \theta)}+\frac{4 B}{r^{3}}(1+\nu) \sin \theta \cos \theta$

$\sigma_{r \phi}=\sigma_{\theta \phi}=0$

$B$ is the strength of the Blister field. $P$ is the applied load of the indenter. Sellappan et al. proposed a set of parameters for Yoffe's stresses [18]. Table 4 presents these parameters. Several input parameters in Sellappan et al. model include: (1) $\beta$ governs the
Blister fields strength; (2) $V_{i}^{m}$ is an estimate of the indent volume disregarding elastic recover; (3) $a$ is an estimate of the half diagonal of the projected surface area of an indent; and (4) $\Psi$ is the angle of the indenter.

Fig. 21 (a) reveals theoretical stress calculations as presented by Sellappan et al. [18] for loading (hashed line) and unloading (solid line) stresses when $E / H=11.6$. Sellappan et al. proposed this fit for $E / H_{V}$ values ranging between 10.3 and 12.8 . Three data points herein fit this requirement (SBN 14, SBN 25 and SBN 63). Fig. 21 (b) depicts the loading stress for these three data points using experimental results for $V_{i}^{-}, a, V_{R}, V_{P}, \nu, E$ and $H_{V}$ (Tables 5,1 and 2). This permits a comparison with Sellappan's model. Stresses for $\sigma_{\theta \theta}(r=a, \theta=0) / H$ and $\sigma_{\phi \phi}$ $(r=a, \theta=\pi / 2) / H$ correspond well. However, discrepancies arises between theoretical values and experimental data for $\sigma_{r r}(r=a, \theta=$ $\pi / 2) / H$ and $\sigma_{r r}(r=a, \theta=0) / H$. The signs of the stresses are consistent, but the magnitude of calculated experimental values is less than theoretical values.

Several factors could cause these discrepancies. Table 5 highlights differences in input parameters of stress equations, which are calculated from experiments and Sellappan's model. One difference of particular importance is the leftwards shift in the $V_{R}$ versus $\nu$ as seen in Fig. 14. This implies that the volume recovery in SBN glasses is less than complex glasses used by Sellappan et al. On the other hand, $V_{P}$ versus $\nu$ fits the spread of the data, yet there are still large differences between the model and experimental values.

Currently, the model assumes that densification and shear flow processes are independent of loading. Thus, this could be one source of uncertainty in the model. Whatever the values of $V_{R}$ and $V_{P}$, the trends are coherent with [18].

Table 5

Comparison of measured and values obtained in [18] (Table 3 and Eqs. (13) and (14)). Negative difference indicates that the model overestimates measured values.

\begin{tabular}{|c|c|c|c|c|c|c|c|c|c|c|c|c|c|}
\hline \multirow[t]{2}{*}{ Name } & \multicolumn{5}{|c|}{ Experimental } & \multicolumn{4}{|c|}{ Model from [18] } & \multicolumn{4}{|c|}{ Percent difference } \\
\hline & $\begin{array}{l}d_{i} \\
(\mu \mathrm{m})\end{array}$ & $\begin{array}{l}V_{i}^{-} \\
\left(\mu \mathrm{m}^{3}\right)\end{array}$ & $V_{R}$ & $V_{P}$ & $\beta$ & $\begin{array}{l}V_{i}^{-} \\
\left(\mu \mathrm{m}^{3}\right)\end{array}$ & $V_{R}$ & $V_{P}$ & $\beta$ & $V_{i}^{-}$ & $V_{R}$ & $V_{P}$ & $\beta$ \\
\hline SBN 12 & 10.5 & 36.7 & 0.528 & 0.163 & 0.31 & 34.54 & 0.704 & 0.157 & 0.14 & $6 \%$ & $-33 \%$ & $4 \%$ & $55 \%$ \\
\hline SBN 25 & 12.025 & 54.8 & 0.308 & 0.256 & 0.44 & 51.88 & 0.508 & 0.239 & 0.25 & $5 \%$ & $-65 \%$ & $7 \%$ & $42 \%$ \\
\hline SBN 30 & 13 & 62 & 0.126 & 0.286 & 0.59 & 65.55 & 0.388 & 0.298 & 0.31 & $-6 \%$ & $-208 \%$ & $-4 \%$ & $47 \%$ \\
\hline SBN 35 & 13.6 & 70.1 & 0.090 & 0.324 & 0.59 & 75.05 & 0.329 & 0.333 & 0.34 & $-7 \%$ & $-265 \%$ & $-3 \%$ & $42 \%$ \\
\hline SBN 14 & 11.25 & 35.2 & 0.343 & 0.113 & 0.54 & 42.48 & 0.686 & 0.164 & 0.15 & $-21 \%$ & $-100 \%$ & $-45 \%$ & $72 \%$ \\
\hline SBN 63 & 11.95 & 49.3 & 0.320 & 0.256 & 0.42 & 50.91 & 0.593 & 0.202 & 0.20 & $-3 \%$ & $-85 \%$ & $21 \%$ & $52 \%$ \\
\hline SBN 59 & 13.1 & 55.3 & 0.300 & 0.163 & 0.54 & 67.07 & 0.565 & 0.214 & 0.22 & $-21 \%$ & $-88 \%$ & $-31 \%$ & $59 \%$ \\
\hline SBN 55 & 13.625 & 56.8 & 0.280 & 0.158 & 0.56 & 75.46 & 0.415 & 0.283 & 0.30 & $-33 \%$ & $-48 \%$ & $-79 \%$ & $46 \%$ \\
\hline
\end{tabular}




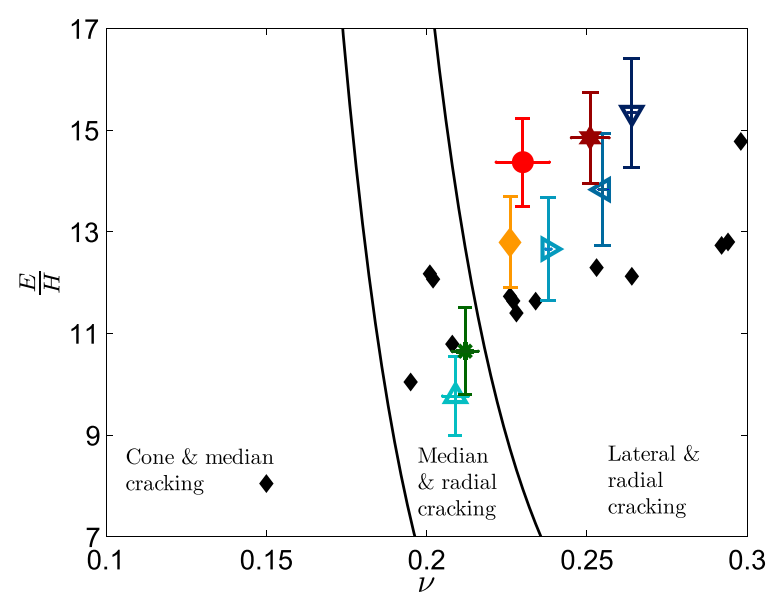

Fig. 22. Dependence of $\nu$ on the transitions from cone/median to median cracks and from median to lateral radial cracking. Black points represent values from Sellappan's paper [18].

Last but not the least, it is not unexpected that calculated stresses overestimate experimental values. The current expression for the Blister field (presented in Table 3) does not account for elastic recovery. Hence, the indentation volume (as estimated from the geometrical volume with contact at maximum load) is larger than the recovered volume. This means that both $V_{i}^{-}$and $\beta$ are overestimated.

Variations in the chemical composition change the morphology of indentation print, specially the nature and the probability of crack appearance, as presented in Fig. 4. For example the nature and the intensity of the residual stresses impact directly median cracks. This is because they originate from the subsurface and are directly impacted by the intrinsic deformation [57]. Table 5 reveals variations in densification and shear flow processes. These variations lead to variations in the stress field (Fig. 21) which alters the crack appearance probability for SBN glasses (Fig. 8). This can explain the drastic variations in the crack appearance behavior observed from the SBN 12 to SBN 25. Thus, small variations in the chemical composition lead to a significant change in the cracking behavior [54].

Fig. 22 presents the data along with the types of cracking predicted by Sellappan et al. [18]. SBN 12 and SBN 14 require higher forces to initiate cracks off the corners of the indenter with SBN 12 never reaching $100 \% P_{C}$. Thus a transition in cracking behavior from SBN 12 to the other glasses (which obtain a $P_{C}=100 \%$ at low forces) is feasible.

The SBN 12 presents a singular behavior regarding the SBN series herein. No cracks are visible after Vickers's indentations at $50 \mathrm{~g}$. Furthermore, increasing the load did not facilitate the development of cracks popping up from the indentation corners. Complementary measurements of $V_{R}$ and $V_{P}$ highlight the important contribution of the densification process during the indentation. This changes the mechanism yielding to the crack formation: (1) change in the residual stresses resulting from these processes, and (2) appearance of other types of cracks under indentation which would limit the propagation of visible cracks.

\section{Conclusion}

A glass's chemical composition impacts its behavior under a sharp indenter. Glasses with a higher concentration of network formers exhibit higher hardness values. The addition of sodium in the composition (for glasses studied herein) induces NBOs in the silicate/borate network and changes the coordination of boron. As a consequence, the indenter penetrates deeper at a given load.

A good macroscopic parameter to link the glass structural variations to its continuum scale properties is $\nu$. Densification processes favor smaller values of $\nu$, i.e. strongly connected network, whereas shear flow process becomes predominant as the alkali content increases.
The two processes impact the indentation pattern and the cracking behavior. Sellappan et al. [18] model provides an estimation of stresses during loading and unloading. Because shear flow process increases with sodium concentration, stresses during loading and unloading increasingly favor lateral-radial cracks. As a consequence, $K_{C}^{V I F}$ is indirectly proportional to $\nu$.

\section{Acknowledgments}

The authors are grateful to T. Bernard for technical assistance. CEA, AREVA, Triangle de la Physique (RTRA grant IMAFMP) and Ile-deFrance (C'Nano and ISC-PIF grant IMAFMP) have supported this research work.

\section{Appendix A. Table of symbols and their meanings}

Table 6

Table of symbols.

\begin{tabular}{|c|c|c|}
\hline Symbol & Meaning & Equation \\
\hline SBN & Sodium BoroSilicate $\left(\left[\mathrm{SiO}_{2}\right]-\left[\mathrm{B}_{2} \mathrm{O}_{3}\right]-\left[\mathrm{Na}_{2} \mathrm{O}\right]\right)$ & \\
\hline NBO & Non-bridging oxygen atoms & \\
\hline$H_{V}$ & Material hardness & 5 \\
\hline$K_{C}$ & Fracture toughness as measured in vacuum & \\
\hline$K_{C}^{I N D}$ & $K_{C}$ arises from indentation studies. & 6 \\
\hline$K_{C}^{V I F}$ & Vickers's indentation fracture toughness & 7 \\
\hline$\nu$ & Poisson's ratio & 3 \\
\hline$[\cdot]$ & $\mathrm{mol} \%$ & \\
\hline$R_{\mathrm{SBN}}$ & $\frac{\left[\mathrm{Na}_{2} \mathrm{O}\right]}{\mathrm{B}_{2} \mathrm{O}_{3}}$, ratio of mol\% of $\left[\mathrm{Na}_{2} \mathrm{O}\right]$ to $\mathrm{mol} \%$ of $\left[\mathrm{B}_{2} \mathrm{O}_{3}\right]$ & \\
\hline$R_{\max }^{\mathrm{SBN}}$ & $\begin{array}{l}\text { For } R_{\mathrm{SBN}}<R_{\mathrm{max}}^{\mathrm{SBN}}, \mathrm{Na}^{+} \text {ions predominantly cause } \\
\text { fully coordinated }{ }^{[3]} \mathrm{B} \text { to transform into fully } \\
\text { coordinated }{ }^{[4]} \mathrm{B} \text {. For } R_{\mathrm{SBN}}>R_{\mathrm{max}}^{\mathrm{SBN}} \text {, extra } \mathrm{Na}^{+} \text {ions } \\
\text { cause fully coordinated }{ }^{[4]} \mathrm{B} \text { to transform into } \\
{ }^{[3]} \mathrm{B} \text { with } \mathrm{NBO} \text { and it causes NBO in the silica } \\
\text { network. }\end{array}$ & $R_{\max }^{\mathrm{SBN}}=0.5+\frac{K_{\mathrm{SBN}}}{16}$ \\
\hline$K_{\mathrm{SBN}}$ & $\frac{\left[\mathrm{SiO}_{2}\right]}{\left[\mathrm{B}_{2} \mathrm{O}_{3}\right]}$, ratio of $\mathrm{mol} \%$ of $\left[\mathrm{SiO}_{2}\right]$ to $\mathrm{mol} \%$ of $\left[\mathrm{B}_{2} \mathrm{O}_{3}\right]$ & \\
\hline$T_{g}$ & Glass transition temperature & \\
\hline E & Young's modulus & 2 \\
\hline$\langle C N\rangle$ & Mean coordination number of the boron atoms & \\
\hline${ }^{[4]} \mathrm{B}$ & $\begin{array}{l}\text { The concentration of }{ }^{[4]} \mathrm{B} \text { per volume unit } \\
\text { deduced from NMR measurements and ICP-AES } \\
\text { results }\end{array}$ & \\
\hline$N_{\mathrm{NBO}}$ & Number of NBO per volume unit & 4 \\
\hline$N_{\mathrm{Na}}$ & Number of $\mathrm{Na}^{+}$ions acting as network modifiers & \\
\hline$N_{[4]}^{[4]}$ & $\begin{array}{l}\text { Each }{ }^{[4]} \mathrm{B} \text { structural unit has one } \mathrm{Na}^{+} \text {ion } \\
\text { attaching to it. Thus, this equates to the number } \\
\text { of } \mathrm{Na}^{+} \text {ion acting as a network compensator. }\end{array}$ & \\
\hline$\rho$ & Density of sample & 1 \\
\hline$\rho_{w}$ & Density of water & \\
\hline$m_{d}$ & Mass of samples in air at $24^{\circ} \mathrm{C}$ & \\
\hline$m_{w}$ & Mass of samples in water at $24{ }^{\circ} \mathrm{C}$ & \\
\hline$V_{L}$ & longitudinal Velocities & \\
\hline$V_{T}$ & transverse Velocities & \\
\hline$P_{C}$ & Crack appearance probability & \\
\hline$P$ & Indentation load & \\
\hline$P_{\text {id }}$ & Residual indentation depth & \\
\hline$P_{a d}$ & Residual indentation depth after annealing & \\
\hline$d_{i}$ & $\begin{array}{l}\text { An indentation diagonal length on one indent } \\
\text { (note there are } 2 \text { per indent) }\end{array}$ & \\
\hline$d_{a}$ & $\begin{array}{l}\text { An indentation diagonal length on one indent } \\
\text { (note there are } 2 \text { per indent) after annealing }\end{array}$ & \\
\hline$d$ & The mean of $\left\langle d_{i}\right\rangle$ values obtained for one indent. & \\
\hline$V_{i}^{-}$ & Indentation volume below the free surface & \\
\hline$V_{i}^{+}$ & $\begin{array}{l}\text { Indentation volume above the free surface, i.e. } \\
\text { pile-up }\end{array}$ & \\
\hline$V_{a}^{-}$ & $\begin{array}{l}\text { Indentation volume below the free surface after } \\
\text { annealing }\end{array}$ & \\
\hline$V_{a}^{+}$ & $\begin{array}{l}\text { Indentation volume above the free surface after } \\
\text { annealing, i.e. pile-up }\end{array}$ & \\
\hline$c_{i}$ & $\begin{array}{l}\text { The crack length measured from the indentation } \\
\text { center. }\end{array}$ & \\
\hline c & $\begin{array}{l}\text { The average distance }\left(\left\langle c_{i}\right\rangle\right) \text { from the indentation } \\
\text { center to the crack tip }\end{array}$ & \\
\hline
\end{tabular}

(continued on next page) 
Table 6 (continued)

\begin{tabular}{|c|c|c|}
\hline Symbol & Meaning & Equation \\
\hline$C_{R}$ & Crack resistance: the load where $P_{C}$ exceeds 50\% & \\
\hline$V_{R}$ & Recovered volume ratio & 8 \\
\hline$V_{P}$ & $\begin{array}{l}\text { Volume-conserving shear flow ratio as deter- } \\
\text { mined in the pile-up }\end{array}$ & 9 \\
\hline$P_{f}$ & Packing fraction & 10 \\
\hline$\rho_{t}$ & Minimal theoretical density & 11 \\
\hline$V_{i}$ & Ideal volume for an oxide & 12 \\
\hline$N_{A}$ & Avogadro number & \\
\hline$r_{A}$ & Ionic radii of the cation in the oxide $\left[\mathrm{A}_{\mathrm{x}} \mathrm{O}_{\mathrm{y}}\right]$ & \\
\hline$r_{O}$ & The ionic radii of anion in the oxides $\left[\mathrm{A}_{\mathrm{x}} \mathrm{O}_{\mathrm{y}}\right]$ & \\
\hline $\begin{array}{c}\left(\alpha_{R}, \beta_{R}, \chi_{R}\right. \\
\left.\delta_{R}\right)\end{array}$ & $\begin{array}{l}\text { Fitting parameters for the sigmoid fit of } V_{R} \text { for } \\
\text { Eq. (13) }\end{array}$ & \\
\hline$\left(\alpha_{P}, \beta_{P}, \chi_{P}\right)$ & $\begin{array}{l}\text { Fitting parameters for the sigmoid fit of } V_{P} \text { for } \\
\text { Eq. (14) }\end{array}$ & \\
\hline $\begin{array}{l}\sigma_{r r}, \sigma_{\theta \theta}, \sigma_{\phi \phi} \\
\quad \sigma_{r \theta}, \sigma_{r \phi}, \sigma_{\theta \phi}\end{array}$ & Yoffe's stress field in spherical polar coordinates & $\begin{array}{l}15,16,17,18 \\
19\end{array}$ \\
\hline B & Strength of blister field & Table 3 \\
\hline$\beta$ & Sellappan's blister field strength & Table 3 \\
\hline$V_{i}^{m}$ & Volume of indent disregarding elastic recovery & Table 3 \\
\hline$a$ & Half the diagonal of the projected surface area & Table 3 \\
\hline$\Psi$ & Apical angle of the indenter & Table 3 \\
\hline
\end{tabular}

\section{Appendix B. Data used to calculate $E$ and $\nu$}

\section{Table 7}

$V_{L}, V_{T}, E$, and $\nu$ calculated for each SBN glass. Average values result from 3 measurements of $V_{L}$ and $V_{T}$ during different times of the year. Standard deviations result from these measurements. Error bars in the figures depict one standard deviation.

\begin{tabular}{lllll}
\hline Name & $V_{L}(\mathrm{~m} / \mathrm{s})$ & $V_{T}(\mathrm{~m} / \mathrm{s})$ & $E(\mathrm{GPa})$ & $\nu$ \\
\hline SBN 12 & $3074_{ \pm 17}$ & $1835_{ \pm 6}$ & $80.1_{ \pm 0.03}$ & $0.208_{ \pm 0.06}$ \\
SBN 25 & $3053_{ \pm 10}$ & $1789_{ \pm 8}$ & $80.3_{ \pm 0.04}$ & $0.238_{ \pm 0.008}$ \\
SBN 30 & $2938_{ \pm 6}$ & $1713_{ \pm 8}$ & $74.7_{ \pm 0.05}$ & $0.255_{ \pm 0.001}$ \\
SBN 35 & $3057_{ \pm 15}$ & $1727_{ \pm 6}$ & $76.7_{ \pm 0.04}$ & $0.264_{ \pm 0.002}$ \\
SBN 14 & $3049_{ \pm 21}$ & $1851_{ \pm 32}$ & $81.8_{ \pm 1.02}$ & $0.210_{ \pm 0.015}$ \\
SBN 63 & $3046_{ \pm 11}$ & $1809_{ \pm 8}$ & $81.9_{ \pm 0.06}$ & $0.226_{ \pm 0.009}$ \\
SBN 59 & $2968_{ \pm 24}$ & $1767_{ \pm 15}$ & $77.2_{ \pm 0.03}$ & $0.230_{ \pm 0.007}$ \\
SBN 55 & $2931_{ \pm 20}$ & $1689_{ \pm 4}$ & $72.8_{ \pm 0.06}$ & $0.251_{ \pm 0.005}$ \\
\hline
\end{tabular}

\section{References}

[1] T. Rouxel, T. Hammouda, A. Moréac, Poisson's ratio and the densification of glass under high pressure, Phys. Rev. Lett. 100 (2008) 225501.

[2] D. Uhlmann, Densification of alkali silicate glasses at high pressure, J. Non-Cryst. Solids 13 (1973) 89-99.

[3] F. Ernsberg, Role of densification in deformation of glasses under point loading, J. Am. Ceram. Soc. 51 (1968) 545.

[4] J. Mackenzie, High-pressure effects on oxide glasses. 1. densification in rigid state, J. Am. Ceram. Soc. 46 (1963) 461-470.

[5] K. Peter, Densification and flow phenomena of glass in indentation experiments, J. Non-Cryst. Solids 5 (1970) 103-115.

[6] J. Hagan, S. Van der Zwaag, Plastic processes in a range of soda-lime-silica glasses, J. Non-Cryst. Solids 64 (1984) 249-268.

[7] J. Hagan, Shear deformation under pyramidal indentations in soda-lime glass, J. Mater. Sci. 15 (1980) 1417-1424.

[8] J.T. Hagan, M.V. Swain, The origin of median and lateral cracks around plastic indents in brittle materials, J. Phys. D. Appl. Phys. 11 (15) (1978) 2091. http://dx. doi.org/10.1088/0022-3727/11/15/007.

[9] M. Bertoldi, M. Sglavo, Soda-borosilicate glass: normal or anomalous behavior under Vickers indentation, J. Non-Cryst. Solids 344 (2004) 51-59.

[10] G. Buscarino, S. Agnello, F.M. Gelardi, Structural modifications induced by electron irradiation in SiO2 glass: local densification measurements, Europhys. Lett. 87 (2009) 26007.

[11] T. Rouxel, J.-C. Sangleboeuf, C. Moysan, B. Truffin, Indentation topometry in glasses by atomic force microscopy, J. Non-Cryst. Solids 344 (2004) 26-36.

[12] B. Lawn, A.G. Evan, D.B. Marshall, Elastic-plastic indentation damage in ceramics the median-radial crack system, J. Am. Ceram. Soc. 63 (9-10) (1980) 574-581. http://dx.doi.org/10.1111/j.1151-2916.1980.tb10768.x.

[13] A. Arora, D. Marshall, B. Lawn, Indentation deformation/fracture of normal and anomalous glasses, J. Non-Cryst. Solids 31 (1979) 415-428.
[14] J. Hagan, Micromechanics of crack nucleation during indentations, J. Mater. Sci. 14 (1979) 2975-2980.

[15] J.D. Mackenzie, High-pressure effects on oxide glasses, J. Am. Ceram. Soc. 46 (10) (1963) 461-470.

[16] S. Yoshida, J.-C. Sangleboeuf, T. Rouxel, Quantitative evaluation of indentationinduced densification in glass, J. Mater. Res. 20 (2005) 3404-3412.

[17] S. Yoshida, J.-C. Sangleboeuf, T. Rouxel, Indentation-induced densification of soda-lime silicate glass, Int. J. Mater. Res. 98 (2007) 360-364.

[18] P. Sellappan, T. Rouxel, F. Celarie, E. Becker, P. Houizot, R. Conradt, Composition dependence of indentation deformation and indentation cracking in glass, Acta Mater. 61 (2013) 5949-5965.

[19] M. Barlet, A. Kerrache, J.-M. Delaye, C. Rountree, $\mathrm{SiO}_{2}-\mathrm{Na}_{2} \mathrm{O}-\mathrm{B}_{2} \mathrm{O}_{3}$ density: a comparison of experiments, simulations, and theory, J. Non-Cryst. Solids 382 (0) (2013) 32-44. http://dx.doi.org/10.1016/j.jnoncrysol.2013.09.022 (URL http://www. sciencedirect.com/science/article/pii/S0022309313004869).

[20] F. Angeli, T. Charpentier, D. de Ligny, C. Cailleteauz, Boron speciation in soda-lime borosilicate glasses containing zirconium, J. Am. Ceram. Soc. 93 (9) (2010) 2693-2704. http://dx.doi.org/10.1111/j.1551-2916.2010.03771.x.

[21] C. Hermansen, J. Matsuoka, S. Yoshida, H. Yamazaki, Y. Kato, Y. Yue, Densification and plastic deformation under microindentation in silicate glasses and the relation to hardness and crack resistance, J. Non-Cryst. Solids 364 (0) (2013) 40-43. http://dx.doi.org/10.1016/j.jnoncrysol.2012.12.047 (URL http://www.sciencedirect. com/science/article/pii/S0022309313000094).

[22] P. Chantikul, G. Anstis, B. Lawn, D. Marshall, A critical-evaluation of indentation techniques for measuring fracture-toughness. 2. Strength method, J. Am. Ceram. Soc. 64 (9) (1981) 539-543. http://dx.doi.org/10.1111/j.1151-2916.1981.tb10321.x.

[23] D.B. Marshall, A.G. Evans, Reply to comment on elastic/plastic indentation damage in ceramics: the median/radial crack system, J. Am. Ceram. Soc. 64 (12) (1981) C-182-C-183. http://dx.doi.org/10.1111/j.1151-2916.1981.tb15909.x.

[24] D. Marshall, B. Lawn, Residual stress effects in sharp contact cracking part 1 indentation fracture mechanics, J. Mater. Sci. 14 (8) (1979) 2001-2012. http://dx.doi.org/ 10.1007/BF00551043.

[25] K. Niihara, A fracture-mechanics analysis of indentation-induced cs palmqvist crack in ceramics, J. Mater. Sci. Lett. 2 (5) (1983) 221-223. http://dx.doi.org/10.1007/ BF00725625.

[26] K. Niihara, R. Morena, D. Hasselman, Evaluation of klc of brittle solids by the indentation method with low crack-to-indent ratios, J. Mater. Sci. Lett. 1 (1) (1982) 13-16. http://dx.doi.org/10.1007/BF00724706.

[27] K. Niihara, A. Nakahira, T. Hirai, The effect of stoichiometry on mechanicalproperties of boron-carbide, J. Am. Ceram. Soc. 67 (1) (1984) C13-C14.

[28] G. Anstis, P. Chantikul, B. Lawn, D. Marshall, A critical evaluation of indentation technique for measuring fracture toughness: I, direct crack measurement, J. Am. Ceram. Soc. 64 (1981) 533-538. http://dx.doi.org/10.1111/j.1151-2916.1981.tb10320.x.

[29] J. Lankford, Indentation microfracture in the Palmqvist crack regime - implications for fracture-toughness evaluation by the indentation method, J. Mater. Sci. Lett. 1 (11) (1982) 493-495. http://dx.doi.org/10.1007/BF00721938.

[30] M. Laugier, The elastic plastic indentation of ceramics, J. Mater. Sci. Lett. 4 (12) (1985) 1539-1541. http://dx.doi.org/10.1007/BF00721390.

[31] M. Laugier, New formula for indentation toughness in ceramics, J. Mater. Sci. Lett. 6 (3) (1987) 355-356. http://dx.doi.org/10.1007/BF01729352.

[32] W.J. Weber, H. Matzke, J.L. Routbort, Indentation testing of nuclear-waste glasses, J. Mater. Sci. 19 (8) (1984) 2533-2545. http://dx.doi.org/10.1007/BF00550807.

[33] R.D. Dukino, M.V. Swain, Comparative measurement of indentation fracture toughness with Berkovich and Vickers indenters, J. Am. Ceram. Soc. 75 (12) (1992) 3299-3304. http://dx.doi.org/10.1111/j.1151-2916.1992.tb04425.x.

[34] J.R. Taylor, An Introduction to Error Ana, University Science Books, 1982.

[35] A. Perriot, E. Barthel, G. Kermouche, G. Querel, D. Vandembroucq, On the plastic deformation of soda-lime glass $-\mathrm{a} \mathrm{Cr}^{3+}$ luminescence study of densification, Philos. Mag. 91 (2011) 1245-1255.

[36] A. Perriot, D. Vandembroucq, E. Barthel, V. Martinez, L. Grosvalet, C. Martinet, B. Champagnon, Raman microspectroscopic characterization of amorphous silica plastic behavior, J. Am. Ceram. Soc. 89 (2006) 596-601.

[37] J. Mackenzie, High-pressure effects on oxide glasses. 2. Subsequent heat treatment, J. Am. Ceram. Soc. 46 (1963) 470.

[38] P.W. Bridgman, I. Simon, Effect of very high pressure on glass, J. Appl. Phys. 24 (1953) 405.

[39] F.M. Ernsberger, Role of densification in deformation of glasses under point loading, J. Am. Ceram. Soc. 51 (1968) 545-547.

[40] S. Yoshida, S. Isono, J. Matsuoka, N. Soga, Shrinkage behavior of Knoop indentations in silica and soda-lime-silica glasses, J. Am. Ceram. Soc. 84 (9) (2001) 2141-2143.

[41] G. Hetherington, The viscosity of vitreous silica, Phys. Chem. Glasses 5 (1964) 130

[42] H. Inoue, A. Masuno, Y. Watanabe, K. Suzuki, T. Iseda, Direct calculation of the physical properties of sodium borosilicate glass from its chemical composition using the concept of structural units, J. Am. Ceram. Soc. 95 (1) (2012) 211-216. http://dx.doi.org/10.1111/j.1551-2916.2011.04964.x.

[43] D. Feil, S. Feller, The density of sodium borosilicate glasses related to atomic arrangements, J. Non-Cryst. Solids 119 (1) (1990) 103-111. http://dx.doi.org/10.1016/ 0022-3093(90)90246-I.

[44] K. BUDHWANI, S. Feller, Density model for the lithium, sodium and potassium borosilicate glass systems, Phys. Chem. Glasses 36 (4) (1995) 183-190.

[45] W.J. Dell, P.J. Bray, S.Z. Xiao, B-11 NMR-studies and structural modeling of $\mathrm{Na}_{2} \mathrm{O}$ $\mathrm{B}_{2} \mathrm{O}_{3}-\mathrm{SiO}_{2}$ glasses of high soda content, J. Non-Cryst. Solids 58 (1) (1983) 1-16. http://dx.doi.org/10.1016/0022-3093(83)90097-2.

[46] B.C. Bunker, D.R. Tallant, R.J. Kirkpatrick, G. Turner, Multinuclear nuclear-magneticresonance and Raman investigation of sodium borosilicate glass structures, Phys. Chem. Glasses 31 (1) (1990) 30-41. 
[47] H. Ji, E. Robin, T. Rouxel, Compressive creep and indentation behavior of plasticine between 103 and 353 K, Mech. Mater. 41 (2009) 199-209.

[48] R.L. Henderson, N.W. Ashcroft, Perturbation theory of structure in mixtures near phase separation, Phys. Rev. A 13 (1976) 859-871.

[49] T. Rouxel, Elastic properties and short- to medium-range order in glasses, J. Am. Ceram. Soc. 10 (2007) 3019-3039. http://dx.doi.org/10.1111/j.1551-2916.2007. 01945.x.

[50] A. Makishima, J.D. Mackenzie, Direct calculation of Young's modulus of glass, J. Non-Cryst. Solids 12 (1) (1973) 35-45. http://dx.doi.org/10.1016/00223093(73)90053-7.

[51] D. Kilymis, J.-M. Delaye, Deformation mechanisms during nanoindentation of sodium borosilicate glasses of nuclear interest, J. Chem. Phys. 141 (1) (2014) 014504.

[52] D. Kilymis, J.-M. Delaye, Nanoindentation studies of simplified nuclear glasses using molecular dynamics, J. Non-Cryst. Solids. 401 (2014) 147-153.
[53] T. Rouxel, H. Ji, V. Keryvin, T. Hammouda, S. Yoshida, Poisson's ratio and the glass network topology - relevance to high pressure densification and indentation behavior, Adv. Mater. Res. 39-40 (2008) 137-146.

[54] P. Sellappan, Fissuration par indentation des verres: influence de la composition et renforcement par des particules de diamants(Ph.D. thesis) Université de Rennes 1, 2011.

[55] Y. Kato, H. Yamazaki, S. Yoshida, J. Matsuoka, Effect of densification on crack initiation under Vickers indentation test, J. Non-Cryst. Solids 356 (35-36) (2010) 1768-1773. http://dx.doi.org/10.1016/j.jnoncrysol.2010.07.015.

[56] E. Yoffe, Elastic stress fields caused by indentation brittle materials, Philos. Mag. A 46 (1982) 617-627.

[57] H. Ishikawa, N. Shinkai, Critical load for median crack initiation in Vickers indentation of glasses, J. Am. Ceram. Soc. 65 (8) (1982) C124-C127. http://dx.doi.org/10. 1111/j.1151-2916.1982.tb10496.x. 